\title{
Alloy 718 Subsea Bolt in Relation to Surface Cracking: A Microstructural Perspective
}

\author{
B. Saleem*, H. B. Dong, V. Patel \\ School of Engineering, University of Leicester, Leicester, LE1 7RH, UK \\ Email: `bs289@leicester.ac.uk, hd38@leicester.ac.uk, vp118@leicester.ac.uk
}

How to cite this paper: Saleem, B., Dong, H.B. and Patel, V. (2020) Alloy 718 Subsea Bolt in Relation to Surface Cracking: A Microstructural Perspective. Materials Sciences and Applications, 11, 787-816. https://doi.org/10.4236/msa.2020.1112053

Received: June 28, 2020

Accepted: November 30, 2020

Published: December 3, 2020

Copyright $\odot 2020$ by author(s) and Scientific Research Publishing Inc. This work is licensed under the Creative Commons Attribution International License (CC BY 4.0).

http://creativecommons.org/licenses/by/4.0/ (c) (i) Open Access

\begin{abstract}
The brittle fracture mode close to the surface of Inconel 718 subsea bolts is closely related to their nanostructure. When the bolts are used subsea under cathodic protection, hydrogen evolves. Intergranular precipitates and points of intersection of slip lines always held responsible for hydrogen enhanced decohesion. However, thus far, little attention has been paid to the bolts manufacturing method and to the characterization of the role of subsurface oversized nanoprecipitates on transgranular surface cracking. As-received subsea bolts were analyzed using multi-scale observation techniques such as focused ion beam milling, scanning electron microscopy, transmission electron microscopy, and in-air strain rate tensile tests. The results further demonstrated that under identical API aging, there was a difference in the morphological precipitation and strength of 718 as a bolt and rectangular billet. For the 718 rectangular billets, discrete intergranular stable $\delta / \mathrm{MC}$ carbides precipitate and only $\gamma^{\prime}$ of 10 $20 \mathrm{~nm}$ was observed for the bulk and subsurface. Whereas, for the CRA subsea bolt, $\gamma^{\prime}$ was approximately $30 \mathrm{~nm}, \gamma^{\prime \prime}$ was $30-50 \mathrm{~nm}$ for the bulk $(370 \mathrm{HV}) ; \gamma^{\prime}$ was approximately $50 \mathrm{~nm}$ and $\gamma^{\prime \prime}$ was $50-100 \mathrm{~nm}$ at subsurface $(400 \mathrm{HV})$. As-received subsea bolts were investigated at subsurface $(10 \mu \mathrm{m}$ from the surface) at the thread and shank region, which revealed transgranular sheared oversized $\sim 50 \mathrm{~nm} \gamma^{\prime}$ (with dislocation networks) and metastable $\gamma^{\prime \prime}>100 \mathrm{~nm}$ particles, respectively. Thus, an effort was made to develop the hydrogen-assisted surface cracking theory for bolts.
\end{abstract}

\section{Keywords}

Inconel 718, Subsea Bolts, Hydrogen Embrittlement, $\gamma^{\prime}$, Transgranular, Surface Cracking 


\section{Introduction}

\subsection{Background Problem}

Nickel alloy Inconel 718 is used in deep subsea wells in high pressure, high temperature, and corrosive environments as bolts, drill tools, hangers, packers, and subsurface safety valves for extended long-term exposure to stress ( $>70 \%$ yield strength) [1] [2]. Historically, bolts for subsea production systems met manufacturer quality standard in accordance with API Spec 6A applicable for surface wellhead and tree equipment; however, sometimes the installation does not conform to standards by overtightening and over loading [2]. In addition, 718 bolts in taperlock flanges of a subsea completion system are cathodically protected by aluminum anodes, which results in the ingress of hydrogen from the surface.

Hydrogen, as an interstitial solute, is considered to have an adverse effect on bolt ductility and strength. Specifically, hydrogen lowers the fracture energy (reduces fracture toughness) of the crack and promotes cleavage brittle fracture. The interaction of hydrogen atoms with the second phase is important and requires understanding at the atomic scale. Several hydrogen embrittlement (HE) mechanisms have already been proposed; however, the most important mechanism for metallic materials (consisting mainly of $\mathrm{Ni}$ and $\mathrm{Fe}$ ) that do not form hydrides are hydrogen enhanced localized plasticity (HELP) [3] [4] and hydrogen enhanced de-cohesion (HEDE) [5] [6]. Thus, for decades, HE has been a problem for alloy 718 when used subsea. To mitigate this issue, alloy 718 for oilfield applications relies on unique chemistry, heat treatment (as per API 6A718 standard spec [7]), and microstructure to resist stress corrosion cracking; however, the microstructure of Inconel 718 bolts strongly depends on the manufacturing sequence. Typically, the subsea bolts of Inconel family are cold rolled and, then, heat-treated; however, this process results in an increase in the localized hardness, lower ductility, discrete grain boundary precipitation, and higher susceptibility to HE [2]. The reason for this abrupt change in mechanical and corrosive properties is attributed to the microstructure where the detrimental role of intergranular precipitates for HE has already been well established [2] [8] [9] [10] [11], and the analysis of 718 service failures has been performed by Cassagne et al. [12]. Moreover, phase kinetic simulations [13] [14] defined the alloy 718 limitations, which led to the development of controlled microstructure for specific applications [1] [7]. It is possible that for 718 subsea bolts under CP, transgranular oversized nanoprecipitates at the outer periphery (subsurface) may be the primary source for crack initiation and intersection of localized dislocation slip lines (DSLs) [15] [16] [17], which leads to the formation of nanovoids at transgranular regions; later, transgranular nanovoids coalescence propagates to intergranular cracks.

\subsection{Chemistry and Microstructure}

The nominal composition of Inconel 718 in wt\% is $52.50-18.50 \mathrm{Fe}-19 \mathrm{Cr}-5.10$ Nb-3.0 Mo-0.5 Al-1.0 Ti-0.08 C [11] [18]. The matrix is composed of face cen- 
tered cubic (FCC) structure, nickel base austenitic phase, which is called gamma $(\gamma)$. It has many solid solution elements such as tungsten, molybdenum, chromium, iron, aluminum, titanium, and cobalt. $\mathrm{Al}$ and $\mathrm{Cr}$, respectively, from $\mathrm{Al}_{2} \mathrm{O}_{3}$ and $\mathrm{Cr}_{2} \mathrm{O}_{3}$ protective oxide films that increase corrosion resistance [19]. It is primarily strengthened by the unique intermetallic, $\mathrm{Ll}_{2}$ ordered) FCC phase, $\gamma^{\prime}$ $\mathrm{Ni}_{3}(\mathrm{Al}, \mathrm{Ti}, \mathrm{Nb})$, by interacting with dislocations [19]. This ordering places $\mathrm{Ni}$ at the face of each unit cell and $\mathrm{Al}, \mathrm{Ti}$, or $\mathrm{Nb}$ at each corner. The $\gamma^{\prime}$ phase is more spherical at low volume fraction and tends to be cubic at higher volume fraction [20] depending upon heat treatment [21]. Hagel and Beattie [22] have observed that $\gamma^{\prime}$ appears as spheres at the $0 \%-0.2 \%$ lattice mismatch, as cubes at the mismatch of approximately $0.5 \%-1.0 \%$, and as plates at the mismatch above approximately $1.25 \% . \gamma^{\prime}$ forms coherent precipitates in the $\gamma$ matrix at approximately $620^{\circ} \mathrm{C}$. $\gamma^{\prime \prime}$ phase provides additional strength and is considered to be the main strengthening agent. $\gamma^{\prime \prime}$ is body centered tetragonal $\mathrm{Ni}_{3} \mathrm{Nb}$ and precipitate in the $\gamma$ matrix at approximately $720^{\circ} \mathrm{C}$. Both $\gamma^{\prime}$ and $\gamma^{\prime \prime}$ have the solvus temperature of approximately $900^{\circ} \mathrm{C}-920^{\circ} \mathrm{C}$ [14] [23]. However, $\gamma^{\prime \prime}$ is a metastable phase, which tends to be replaced by an incoherent stable orthorhombic delta $(\delta)$ phase, $\mathrm{Ni}_{3} \mathrm{Nb}$, after long-term exposure to temperature above $650^{\circ} \mathrm{C}$ [24] [25] [26]. It typically precipitates at $650^{\circ} \mathrm{C}-980^{\circ} \mathrm{C}$ at grain boundaries with thin plates extending to grains [27] and with the solvus temperature of $980^{\circ} \mathrm{C}$ $995^{\circ} \mathrm{C}$. Both $\gamma^{\prime \prime}$ and $\delta$ phases are Nb-based, which implies that $\delta$ phase precipitation occurs with the loss of the $\gamma^{\prime \prime}$ phase. $\delta$ morphology contributes to the loss of strength and hardenability owing to the depletion of $\gamma^{\prime \prime}$, and its presence in the structure has led to increased susceptibility of hydrogen cracking with the loss of fracture strain and notch tensile strength [28] [29] [30]. In addition to these phases, blocky shaped carbides (i.e., $\mathrm{MC}$ carbides, where $\mathrm{M}$ is mostly $\mathrm{Nb}$ and $\mathrm{Ti}$ ) are homogeneously distributed throughout the matrix [31] [32] [33]. Both $\delta$ and $\mathrm{MC}$ carbides inhibit grain growth and prevent grain boundary sliding. Nb is essential in making up all the phases present in alloy 718. It has been determined that the Laves phase requires $10 \%-12 \%$ of $\mathrm{Nb}$; the delta $\delta$ phase requires $6 \%$ $8 \%$ of $\mathrm{Nb} ; \gamma^{\prime \prime}$ needs $4 \%$ of $\mathrm{Nb}$, and $\gamma^{\prime}$ can form at $\mathrm{Nb}$ levels below $4 \%$. The degree of $\mathrm{Nb}$ segregation during ingot or casting solidification depends on the rate of cooling (i.e., the faster the cooling, the lower is the segregation). High temperature homogenization can be used to produce the Laves phase solution and uniformly distribute $\mathrm{Nb}$ throughout the bulk matrix [34]. Sigma phase has hexagonal geometry with the composition formula of $(\mathrm{Cr}, \mathrm{Mo})_{\mathrm{x}}(\mathrm{Ni}, \mathrm{Co})_{\mathrm{y}}$; where $\times$ and y vary from 1 to 7 ; typically, sigma phase grows through $\gamma^{\prime}$ particles. It has a detrimental effect and the plate-like morphology. Sigma phase is the source for crack initiation and propagation, which leads to low temperature brittle fracture. It contains high amount of refractory elements, which are extracted from the $\gamma$ matrix, which results in the loss of solution strengthening [27].

Thermodynamic calculations and kinetic simulations have become important in understanding alloy 718 properties. It is logical to further improve the alloy; 
(a)

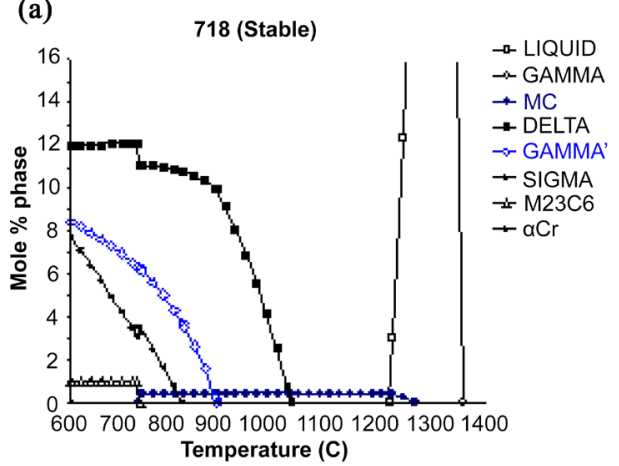

however, oil grade 718 is finely balanced, and small changes in chemistry to avoid $\delta$ or improve corrosion resistance have the risk of forming the Laves phase [1] [34]. It is important to understand that NiFe-based superalloys behave in a more complex way than predominantly Ni-based superalloys. This occurs because the hardening mechanism in the austenitic $\gamma$ matrix involves metastable $\gamma^{\prime}$ $\mathrm{Ni}_{3} \mathrm{Nb}$ along with stable $\gamma^{\prime} \mathrm{Ni}_{3}$ (Al, Ti). Thus, the NiFe-Super database can handle these complex alloys to predict both stable and metastable equilibrium states. The equilibrium phases, which can exist in 718 derivatives, are predicted using the thermodynamic software packages JMatPro and ThermoCalc. The predicted phases that can be present in alloy 718 can be seen in thermodynamic phase diagrams, shown in Figure 1(a) and Figure 1(b). 718 phase diagrams (a) and (b), use the NiFe-Super thermodynamic database, which is designed by Thermotech using JMatPro specifically for Ni-based superalloys containing high Fe content. $\gamma, \gamma^{\prime}, \mathrm{MC}$ and, $\mathrm{M}_{23} \mathrm{C}_{6}$ are commonly predicted for both 718 conditions, as per the heat treatment. Sigma and $\alpha \mathrm{Cr}$ phases are normally present at extended exposure to high temperatures. The time temperature transformation (TTT) diagram for alloy 718 is shown in Figure 1(c).

\subsection{Purpose}

Herein, an extensive microstructural study seeks to investigate alloy 718 that is heat-treated according to API specification in two different product forms, rectangular billet $(\mathrm{RB})$ and subsea bolts. The manufacturing route of bolts involves the API heat treatment followed by cold rolling of threads, whereas, samples extracted from $\mathrm{RB}$ undergo electrical discharge machining followed by the heat treatment. The objective was to perform subsurface cracking analysis for the subsea bolts on the basis of microstructural results and to critically discuss the 718 subsea bolt vulnerability to HE in-service with the already established HAC theories for alloy 718 (which were subjected to different thermochemical treatments and product forms) [2] [8] [9] [10] [11] [12] [15] [16] [17] [35] [36] [37]. The non-standard higher solution treatment at $1250^{\circ} \mathrm{C}$ (because the melting

(b)

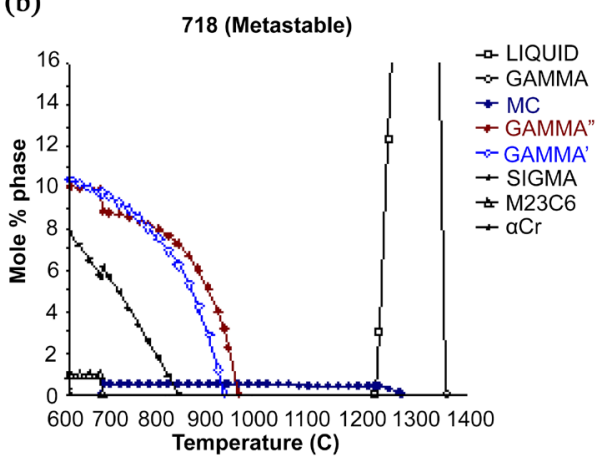

(c)

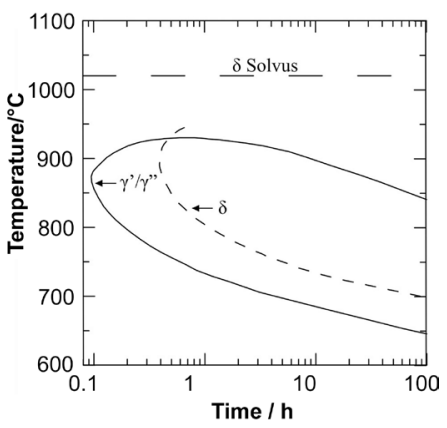

Figure 1. Two alloy 718 phase diagrams from the NiFe-Super database [14]. (a) Mole \% phase plot showing a stable behavior, where $\delta$ phase precipitates and (b) where under sluggish kinetics results in gamma" $\left(\gamma^{\prime \prime}\right)$ precipitation with a preference for $\delta$. Whereas, (c) is a TTT diagram [13] for alloy 718, which reflects the approximate aging times and temperatures required to precipitate $\delta$, $\gamma^{\prime}$, and $\gamma^{\prime \prime}$. 
point of MC carbides is approximately $1200^{\circ} \mathrm{C}[14]$ ) and slightly longer (16 and $25 \mathrm{~h}$ ) aging conditions [13] were used to observe the effect on 718 precipitation in comparison to the API 6A718 aging temperature. Other conventional solution annealing and double aging were added to observe their effect on microstructure when compared to API 6A718. The reason for selecting non-standard heating parameters was to characterize the morphological evolution of second phase particles (i.e., $\gamma^{\prime}$, metastable $\gamma^{\prime \prime}$, stable $\delta, \mathrm{M}(\mathrm{C}, \mathrm{N}) \mathrm{s}$, or any Laves phase) within grains and on grain boundaries. These new heating variants provide more room for observing the PLC effect under slow strain rate testing in the future.

\section{Experimental Methods}

\subsection{Experimental Materials}

Forged Inconel 718 in the product form as a $4 \times \mathrm{RB}\left(100 \times 30 \times 20 \mathrm{~mm}^{3}\right)$ was received from the supplier, and eight separate subsea bolts ( $\Phi$ of $\sim 28 \mathrm{~mm}$ and length of $\sim 150 \mathrm{~mm}$ ), which were heat-treated and then cold rolled to produce threads before deploying them in-service, were received in as-received (AR) condition from the subsea completion system. Optical emission spectroscopy (OES) was performed with thin off cut from the bolts and RBs. The OES results are well within the specifications for the standard UNS NO7718 alloy [7] and are presented in Table 1.

\subsection{Heat Treatment and Sample Preparation}

The 718 specimens were subjected to heat treatment as per conditions described in Table 2. For every sample, type $\mathrm{K}$ thermocouples were peened into holes that

Table 1. Elemental composition of the AR alloy 718 (rectangular billet and bolt).

\begin{tabular}{ccccccccccccc}
\hline 718 & $\mathrm{C}$ & $\mathrm{Si}$ & $\mathrm{Mn}$ & $\mathrm{Cr}$ & $\mathrm{Mo}$ & $\mathrm{Fe}$ & $\mathrm{Al}$ & $\mathrm{Co}$ & $\mathrm{Cu}$ & $\mathrm{Nb}$ & $\mathrm{Ti}$ & $\mathrm{Ni}$ \\
\hline $\begin{array}{c}\text { Element } \\
\text { wt\% }\end{array}$ & 0.025 & 0.11 & 0.05 & 18.1 & 3.09 & 18.7 & 0.48 & 0.14 & 0.04 & 5.06 & 0.98 & 52.6 \\
\hline
\end{tabular}

Table 2. Solution treatment and aging temperatures of 718 Specimens as RB and subsea bolt.

\begin{tabular}{|c|c|c|c|}
\hline Alloy 718 Specimens & Product form & HT Condition & Heat treatment detail \\
\hline $1 \times \mathrm{S} 1$ & $\mathrm{RB}$ & ST Standard & $1035^{\circ} \mathrm{C}-2 \mathrm{~h} \mathrm{AC}$ to $\mathrm{RT}$ \\
\hline $1 \times \mathrm{S} 2$ & $\mathrm{RB}$ & STA Standard (Oilfield Spec. API 6A718) & $1035^{\circ} \mathrm{C}-2 \mathrm{~h} \mathrm{AC} / 788^{\circ} \mathrm{C}-7 \mathrm{~h} \mathrm{AC}$ to $\mathrm{RT}$ \\
\hline $1 \times S 3$ & $\mathrm{RB}$ & ST Non-Standard & $1250^{\circ} \mathrm{C}-2 \mathrm{~h}$ WQ \\
\hline $2 \times S 4$ & $\mathrm{RB}$ & STA Non-Standard & $1250^{\circ} \mathrm{C}-2 \mathrm{~h} \mathrm{WQ} / 788^{\circ} \mathrm{C}-16$ and $25 \mathrm{~h} \mathrm{WQ}$ to $\mathrm{RT}$ \\
\hline $1 \times$ S5 & $\mathrm{RB}$ & STA Standard & $\begin{array}{l}1035^{\circ} \mathrm{C}-1 \mathrm{~h} \mathrm{AC} \text {, then } 718^{\circ} \mathrm{C}-8 \mathrm{~h} \text {, } \\
\text { then } \mathrm{FC} \text { at } 0.433^{\circ} \mathrm{C} / \mathrm{min}-0.933^{\circ} \mathrm{C} / \mathrm{min} \\
\text { to } 621^{\circ} \mathrm{C} \text {, and then hold for } 8 \mathrm{~h}, \mathrm{AC} \text { to } \mathrm{RT}\end{array}$ \\
\hline $4 \times \mathrm{S} 6$ & Bolt $(\Phi 22 \mathrm{~mm})$ & Standard (Oilfield Spec. API 6A718) & $1035^{\circ} \mathrm{C}-2 \mathrm{~h} \mathrm{AC} / 788^{\circ} \mathrm{C}-7 \mathrm{~h} \mathrm{AC}$ to $\mathrm{RT}$ \\
\hline $4 \times \mathrm{S} 7$ & Bolt (Ф $28 \mathrm{~mm})$ & As-Received from subsea (Oilfield Spec. API 6A718) & $1035^{\circ} \mathrm{C}-2 \mathrm{~h} \mathrm{AC} / 788^{\circ} \mathrm{C}-7 \mathrm{~h} \mathrm{AC}$ to $\mathrm{RT}$ \\
\hline
\end{tabular}

NOTE: Symbol "x" represents the number of heat-treated samples for each specimen. Air cooling (AC); furnace cooling (FC); room temperature (RT); solution-treated (ST); solution-treated and aged (STA); water-quenched (WQ); non-standard (NS); rectangular billet (RB). 
were drilled in the reference pieces of nickel alloy, which were put into the furnace along with the actual samples. The temperature of the reference samples was recorded to monitor any temperature change in the actual samples or in the reference samples

From the rectangular billet of alloy 718 , small samples $(20 \times 20 \times 20 \mathrm{~mm})$ were prepared using a spark erosion machine and heat-treated by standard and non-standard heat treatments. The sample S1 was solution-treated in a furnace preheated to $1035^{\circ} \mathrm{C}$ for $2 \mathrm{~h}$ and then air cooled to RT. Then, this sample was removed to prepare it for microstructural investigation, while the S2 samples were solution-treated at $1035^{\circ} \mathrm{C}$ for $2 \mathrm{~h}$ and then put in a furnace (preheated to $788^{\circ} \mathrm{C}$ ) and single aged at this temperature for $7 \mathrm{~h}$ (Oilfield Spec. API 6A718). One S3 sample was solution-treated at $1250^{\circ} \mathrm{C}$ for $2 \mathrm{~h}$ (because of the higher solvus temperature of primary carbides and nitrides [14]) followed by water quenching to RT. Two S4 specimens were solution-treated at $1250^{\circ} \mathrm{C}$ for $2 \mathrm{~h}$, water-quenched, and then one specimen was aged at $788^{\circ} \mathrm{C}$ for $16 \mathrm{~h}$ and another for $25 \mathrm{~h}$, followed by water quenching to RT. The main reason for performing higher-temperature solution treatment was to obtain a higher $\mathrm{Nb}$ and Ti content for $\gamma^{\prime}$ and $\gamma^{\prime \prime}$ precipitation and longer aging times to observe the effect under transmission electron microscopy (TEM) on the coarsening behavior. S5 was solution-treated at temperature similar to $\mathrm{S} 1$ followed by the double aging temperature. The sample was put in a furnace preheated to $718^{\circ} \mathrm{C}$ for $8 \mathrm{~h}$; then, it was furnace cooled at $0.433^{\circ} \mathrm{C} / \mathrm{min}-0.933^{\circ} \mathrm{C} / \mathrm{min}$ to $621^{\circ} \mathrm{C}$, held at this temperature for an additional $8 \mathrm{~h}$, extracted, and air cooled to RT. The AR condition of $8 \times 718$ subsea bolts implied that they were heat-treated, as per the API 6A718 specification for oilfield specification, followed by cold rolling of threads before deploying in subsea. To confirm and replicate the structure of as-received bolts, four AR bolts were rolled to remove the threads, solution-annealed at $1030^{\circ} \mathrm{C}$ for $1 \mathrm{~h}$, and air cooled. Then, the bolts were turned into rolled bars with a diameter of $\sim 22 \mathrm{~mm}$. Then, standard API 6A718 heat treatment was applied to four of the rolled bars. After the completion of the heat treatment, cold rolling of threads was performed at the end. Cross sectional off cuts (2-mm thickness) were extracted from four S6 bolts and four AR S7 subsea bolts for microstructural analysis.

\subsection{Microstructural Studies}

The specimens, which were observed by light microscopy (LM) and scanning electron microscopy (SEM), was grinded and polished using the descending order of abrasive cloths up to the finer grit size of $0.25 \mu \mathrm{m}$. Specimens were mounted with conductive resin prior to grinding and polishing. The Kallings reagent $\left(100 \mathrm{~mL}\right.$ of $\mathrm{HCL}, 100 \mathrm{~mL}$ of ethanol, and $5 \mathrm{~g}$ of $\mathrm{CuCl}_{2}$ ) was used to reveal the microstructure, i.e., grain boundaries and metal carbides. Electrolytic etching was performed with $8 \mathrm{~mL}$ of $\mathrm{H}_{2} \mathrm{SO}_{4}$ and $100 \mathrm{~mL}$ of $\mathrm{H}_{2} \mathrm{O}$ at $2 \mathrm{~V}$ for 3 $s$ to reveal the $\delta / \gamma^{\prime \prime} \gamma^{\prime \prime}$ precipitates. The confirmation of presence of these preci- 
pitates was performed by SEM (spot size 5, operated at $20 \mathrm{KV}$ using the backscatter electron mode) with energy dispersive X-ray (EDX) spectroscopy. The average size of precipitates within the grain and at the grain boundary was measured by evaluating 100 randomly chosen precipitates.

For the TEM analysis, the JEOL 2100 instrument at the department of engineering of University of Leicester was used and operated at the accelerating voltage of $200 \mathrm{KV}$ (beam current of $\sim 102 \mu \mathrm{A}$ ) with the spot size 1 and alpha angle 2. Precipitates were identified by EDX and selected area electron diffraction. The size range of nanoprecipitates was calculated by evaluating 50 randomly chosen precipitates. The electron-transparent samples for the TEM analysis were prepared by two methods i. a twin-jet electro polisher and ii. focused Ion beam (FIB) milling. Thin foils were prepared from each characterization specimen, which were mechanically grounded down by a silicon carbide paper (240 - 1200 grit) to the thickness of less than $100 \mu \mathrm{m}$. The $3-\mathrm{mm}$ foils were punched and subsequently polished by Struers twin-jet electrolytic polishers using a solution of $450 \mathrm{~mL}$ of methanol, $100 \mathrm{~mL}$ of 2-butoxyethanol, and $50 \mathrm{~mL}$ of perchloric acid. The polishing operation was performed at the voltage of $10-15 \mathrm{~V}$, the current of $\sim 45 \mathrm{~mA}$, and with the adjustable jet flow rate of $70-90 \mathrm{~mL} / \mathrm{min}$ or until the electrolyte penetrated through the thickness of the specimen and a hole was created in the middle of the sample. The samples were taken out from the holder and were rinsed in methanol and left on soft paper towels to dry. The second technique for TEM sample extraction used the dual beam SEM/FIB lift-out method. SEM was operated at $20 \mathrm{KV}$ with a spot size 5 , and the ion beam was operated at $30 \mathrm{KV}$ by varying currents from $10 \mathrm{pA}$ to $7 \mathrm{nA}$ depending upon the preparation stage. The method is illustrated in Figure 2(a), where each image from (i) to (xii) reveals the key stages for acquiring TEM electron-transparent foil from the region of interest in the sample. The TEM samples were lifted out from the edge (subsurface) and bulk area of the bolt, whereas the TEM sample from the bulk of RB was prepared using a twin-jet electro polisher and from the edge using FIB. The following points along with the corresponding SEM image describe each stage of FIB:

(i) This is the location of region of interest.

(ii) A platinum layer with the dimensions of $20 \times 2 \times 4 \mu \mathrm{m}$ is deposited at $52^{\circ}$.

(iii) Milling of trenches above and below the platinum deposit.

(iv) Milling of "L" cut at $7^{\circ}$ and cleaning of trenches at $52^{\circ}$.

(v) Tilting back to $7^{\circ}$ to check the "L" cut.

(vi) Attaching the tungsten omniprobe needle with carbon deposition to the right side of the foil. The vertical cut (red dotted line) is made to extract the sample from the trench.

(vii) The foil is attached with the omniprobe needle.

(ciii) Aerial view of the TEM copper grid where foil is to be attached.

(ix) Attachment of the foil using C deposition to the "I"-shaped holder of the TEM grid. 

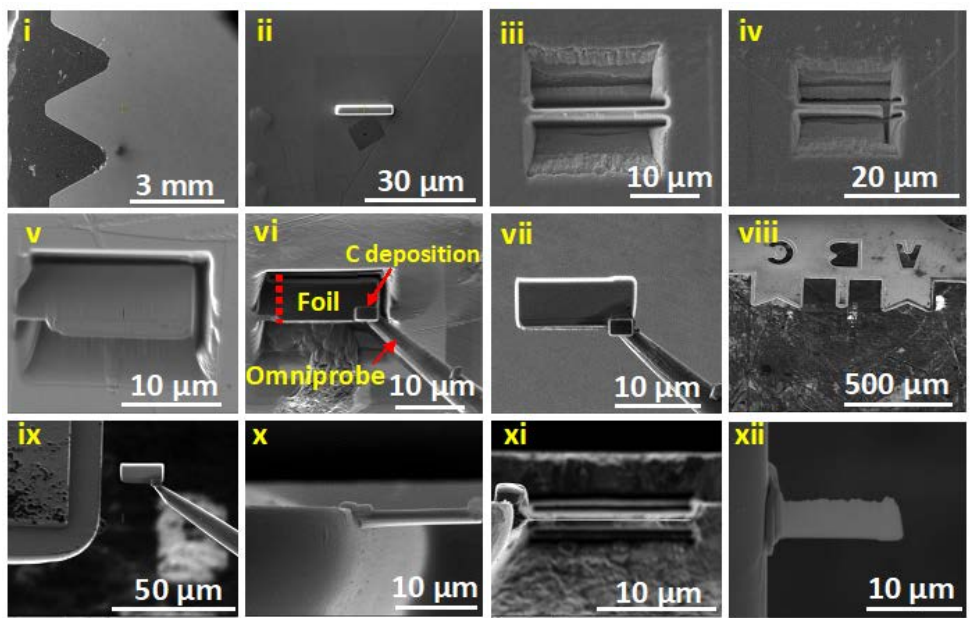

(a)

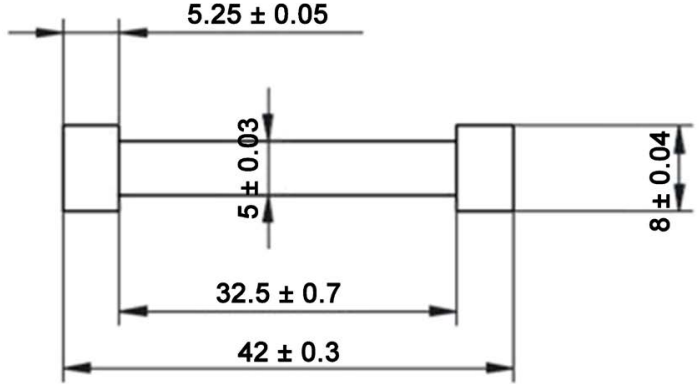

Top plane

(b)

Figure 2. (a) Images (i) to (xii) illustrate the step-by-step guide for preparing TEM electron-transparent foils using the focused ion beam lift-out technique. (b) Schematic illustration of the tensile specimen (unit: $\mathrm{mm}$ )

(x) Attached foil with the TEM grid at the "I"-shaped holder.

(xi) Ion beam image showing the final thinning of the foil with a reduced current.

(xii) SEM image of the electron-transparent foil, which is less than or $~ 100$ $\mathrm{nm}$ and ready for TEM imaging.

\subsection{Mechanical Studies}

The schematic diagram of the tensile specimen is shown in Figure 2(b). Two tensile specimens for each heat treatment were prepared using standard laboratory methods. The tensile specimens from the bolt were extracted from the bulk. The tensile specimens from each alloy were machined to the following dimensions: gage length of $32.5 \mathrm{~mm}$, diameter of $5 \mathrm{~mm}$, and the width of the grip section of $8 \mathrm{~mm}$. The total length of the tensile specimen was $42 \mathrm{~mm}$. The specimens were tested in air using an Instron tensile machine at the strain rate of 2.22 $\times 10^{-4} \mathrm{~s}^{-1}$.

Vickers hardness (HV) measurements were carried out for each characterization specimen. Prior to hardness testing, samples were mounted in resin followed by grinding ( $240-1200$ grit) and polishing up to $0.25 \mu \mathrm{m}$ with colloidal 
silica. Measurements were performed using a diamond pyramid indenter with a force of 5 - $10 \mathrm{kgf}$ (HV5/10). The values were recorded while moving from one end to another. The distance between each indent was kept approximately greater than that of $3 \mathrm{~d}$ spacing, where $\mathrm{d}$ is the indent diameter (either in $\mathrm{x}$ or $\mathrm{y}$ direction), to prevent overlap of strain fields.

\section{Results}

LM, SEM, TEM, and mechanical results were collected for all 718 specimens (from RB and bolt). The primary focus was on the results of SEM and TEM analyses of used CRA bolts, which were used to determine the effect of nanostructure on mechanical properties and surface cracking; then, we established the surface cracking theory for subsea bolts under CP.

\subsection{Variation in Grain Size with Heat Treatment}

Light micrographs for each specimen are shown in Figure 3. The grain size for each heat treatment was evaluated using the LM intercept method and later confirmed with the concentric circles method outlined in the ASTM standard E-112 [38]. To use a statistical approach toward grain size and particle size measurements, at least 15 light and 15 SEM micrographs were considered. There is variation in grain size in 718 specimens from $30 \mu \mathrm{m}$ to $85 \mu \mathrm{m}$. The grain size of $30-$ $35 \mu \mathrm{m}$ was observed for $\mathrm{S} 2_{\mathrm{API}}$ from RB, and $30-40 \mu \mathrm{m}$ for S6 and S7 from CRA bolts. For non-standard heat treatments, an increase in the grain size of $70-85$ $\mu \mathrm{m}$ was observed for S3 and S4 (16 and $25 \mathrm{~h}$, respectively), whereas for S5, the microstructure grain size of 55 - $65 \mu \mathrm{m}$ was observed. However, the light images of bulk and edge sections of CRA bolts (S6 and S7) show no significant change in grain size.

There was no significant difference in the grain size of $S 2_{\mathrm{API}}$ from $\mathrm{RB}$ and of S6 $6_{\mathrm{API}}$ or S7-AR from API bolts. The observation of light microstructures, shown in Figure 3(a), Figure 3(b), and Figure 3(f) for $S 1_{A P I}, S 2_{A P I}, S 6_{A P I}$, and AR clearly indicated the presence of finer grains with a grain size of $30-40 \mu \mathrm{m}$. This implies that RB and the bolt have the same grain size after the API heat treatment. However, the evolution of grain size is observed for non-standard heat-treated specimens S5 $(55-65 \mu \mathrm{m})$ to S3 and S4 $(75-85 \mu \mathrm{m})$. For S3 and S4, this change may be due to an increase in the solution treatment temperature from $1035^{\circ} \mathrm{C}$ to $1250^{\circ} \mathrm{C}$, which results in the dissolution of carbides (as mentioned earlier) and some nitrides back into the matrix, whereas for $\mathrm{S} 5$, a change in the grain size may be due to the double aging after the solution treatment. This treatment may have dissociated primary carbides to form intergranular $\mathrm{M}_{23} \mathrm{C}_{6}$. Moreover, twinning of grains occurred in some specimens (as highlighted in Figure 3), i.e., the same crystal lattice points are shared by separate grains in a symmetrical manner. The plastic deformation mechanism has always been used for Inconel 718 [29] [30]. In addition, grain boundary triple junctions are common in all specimens, both for solution-annealed and aged conditions. 

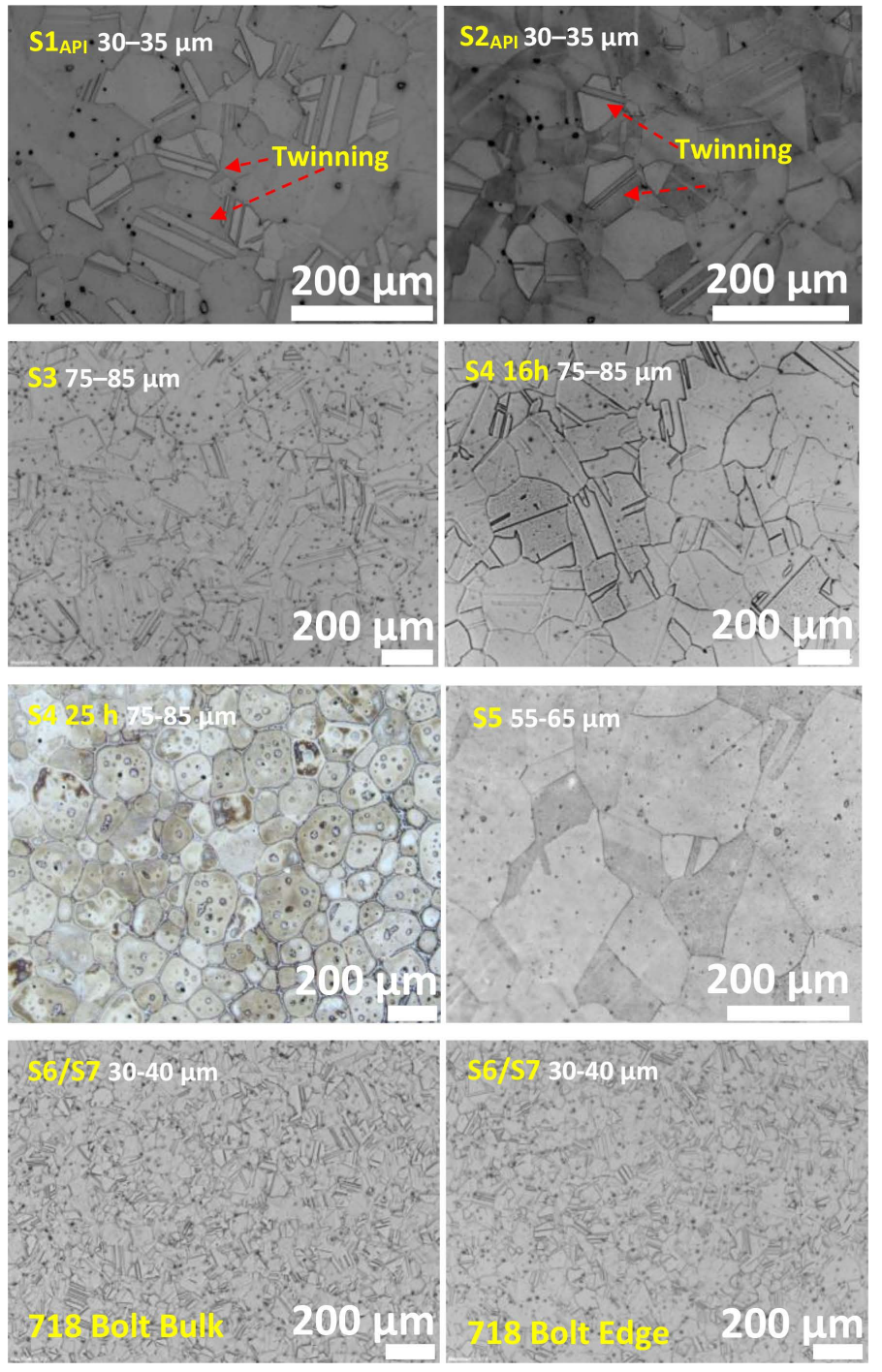

Figure 3. For 718 rectanglar billet specimens ( $\mathrm{S} 1_{\mathrm{API}}, \mathrm{S} 2_{\mathrm{API}}, \mathrm{S} 3, \mathrm{~S} 416 \mathrm{~h}, \mathrm{~S} 425 \mathrm{~h}$, and S5), light microstructures are shown. For S6 and S7 specimens from the 718 bolt, the typical light microstructure shows equiaxed grains from the bulk and edge (subsurface) of the bolt.

\subsection{Intergranular Precipitates and M (C,N)s-Carbides and Nitrides}

The typical SEM images of $\mathrm{S} 1$ and $\mathrm{S} 2_{\mathrm{API}}$ from the $718 \mathrm{RB}$ are shown in Figure 4 and Figure 5, respectively. The solution-treated specimen S1 shows that $\mathrm{M}(\mathrm{C}$, $\mathrm{N}) \mathrm{s}$ are randomly distributed throughout the structure without intergranular precipitation. SEM EDX showed that these precipitates were metal carbides (white) and nitrides (black). Metal carbides were identified as $\mathrm{NbC}$, and metal nitrides as TiN. Whereas, $S 2_{\mathrm{API}}$ had a similar distribution pattern of $\mathrm{M}(\mathrm{C}, \mathrm{N}) \mathrm{s}$ but showed the discrete intergranular precipitation of $\delta$ and $\mathrm{M}_{23} \mathrm{C}_{6}$. The solution-treated specimen $\mathrm{S} 3$ at $1250^{\circ} \mathrm{C}$ showed the dissolution of carbides and some nitrides back into the matrix. Grain boundary precipitation, if any, also dissolved back into the matrix because their solvus temperature was less than $1000^{\circ} \mathrm{C}$. This 


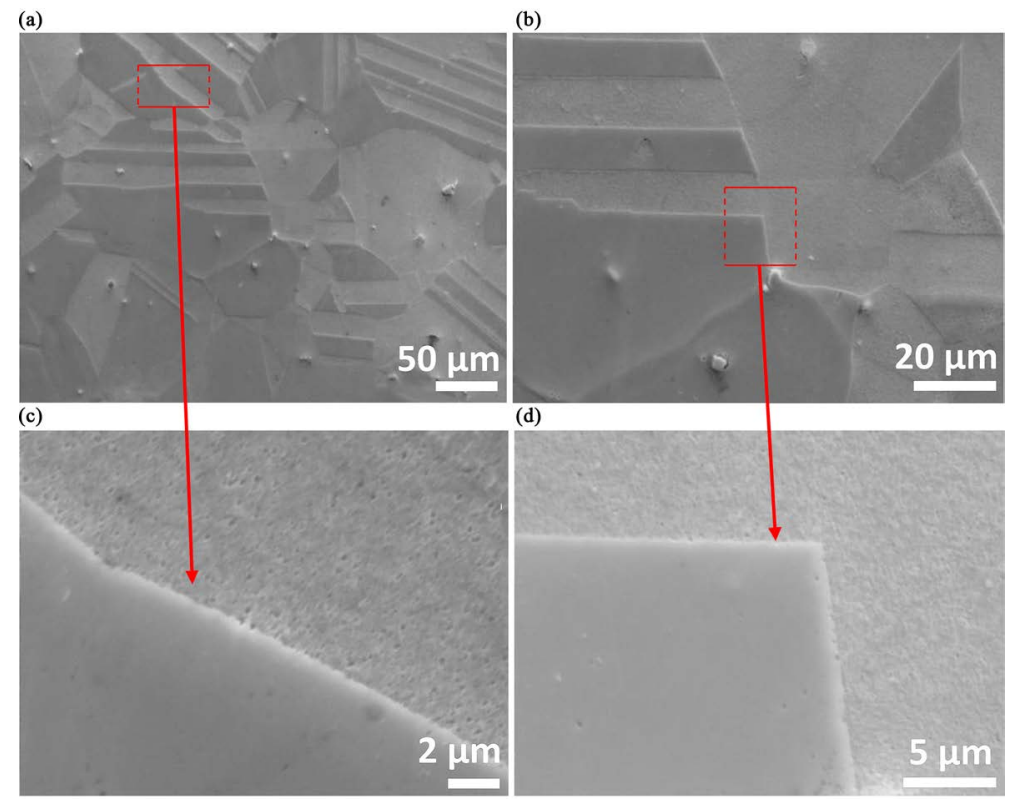

Figure 4. SEM images of specimen $\mathrm{S} 1_{\mathrm{API}}$ from RB: (a) and (b) show $\mathrm{M}(\mathrm{C}, \mathrm{N}) \mathrm{s}(\mathrm{NbC}$; TiN). (c) and (d) show the high magnification of (a) and (b), respectively; as expected, grain boundary precipitation is not observed.
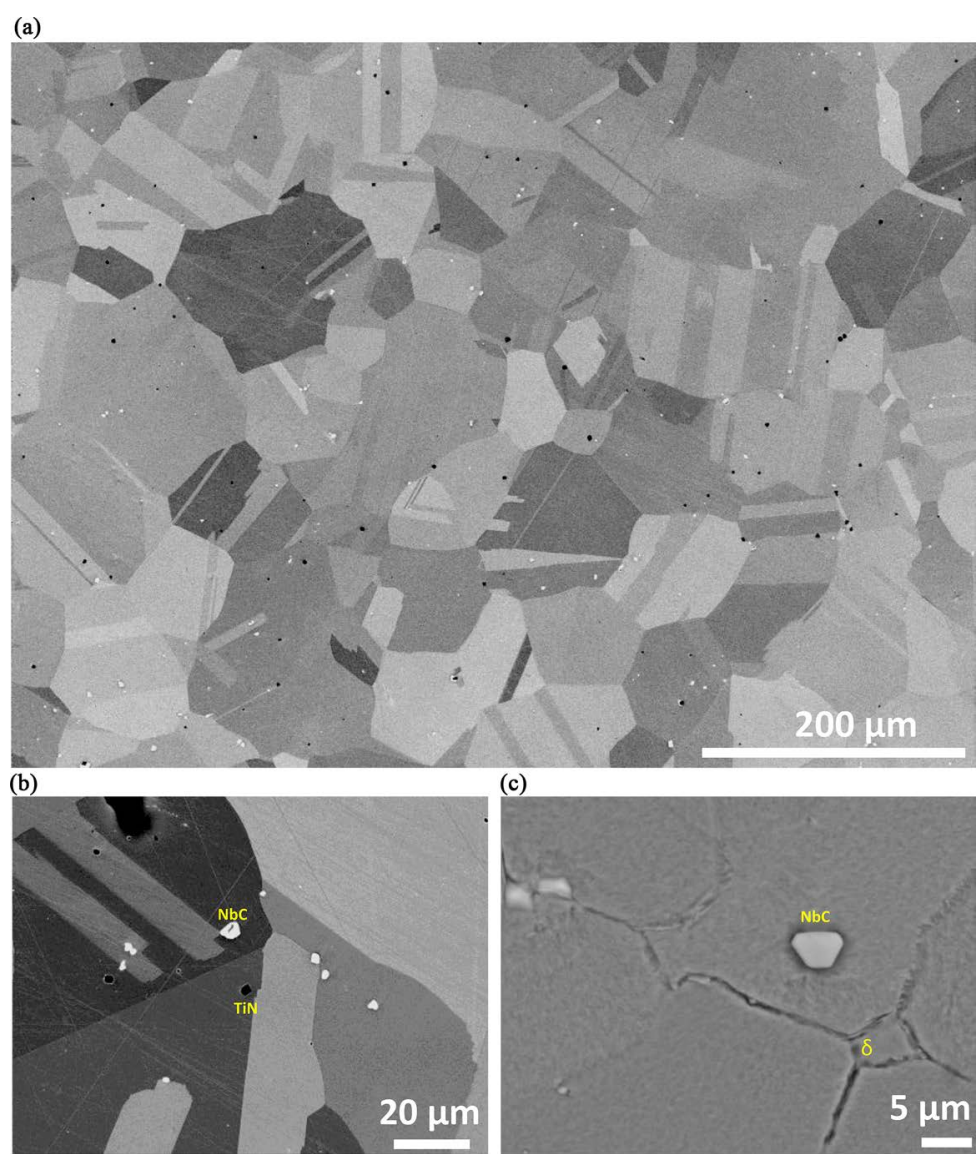

(c)

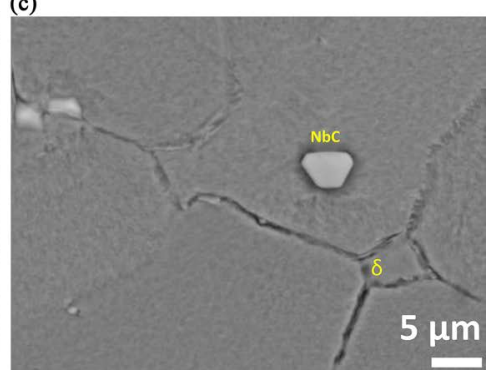

Figure 5. Typical SEM images of specimen $\mathrm{S} 2_{\mathrm{API}}$ from the bulk and subsurface: (a) and (b) show $\mathrm{M}(\mathrm{C}, \mathrm{N}) \mathrm{s}$ (NbC_white and TiN_black). (c) High magnification of intergranular positions showing the discrete acicular (needle like) delta and $\mathrm{M}_{23} \mathrm{C}_{6}$ precipitation. 
is evident from Figure 6(b) and Figure 6(c), which show that grain boundaries do not have second phase precipitation. However, $\mathrm{S} 4$ with the aging time of $16 \mathrm{~h}$ had continuous intergranular needle-like $\delta$ platelets, shown in Figure 7(a) and Figure 7(b); the 25-h treatment produced a continuous Laves phase that was rich in Nb, as seen in Figure 7(c) and Figure 7(d). The solution treatment at $1250^{\circ} \mathrm{C}$ produced a Nb-rich fcc $\gamma$ matrix, which facilitated the continuous precipitation of $\delta$ and Laves phases.

It was observed that S5 and S6 (API bolt) did not have the delta $\delta$ phase (needle platelets) at the grain boundary but S5 contained discrete $\mathrm{M}_{23} \mathrm{C}_{6}$, as shown in Figure 8, whereas $\mathrm{S}_{\mathrm{API}}$ showed the discrete delta $\delta$ phase precipitation at intergranular positions. For specimens S1 and S3, no intergranular precipitation was observed because the solvus temperature of all second phases was below $1000^{\circ} \mathrm{C}$. The solvus temperature of all second phases (e.g., $\gamma^{\prime}, \gamma^{\prime \prime}, \mathrm{M}_{23} \mathrm{C}_{6}$, and MC) was calculated using ThermoCalc simulations.

Typical scanning electron images from the edge and bulk of S6 and S7 CRA bolts from shank and thread regions are shown in Figure 9. Similar to other specimens, $\mathrm{M}(\mathrm{C}, \mathrm{N}) \mathrm{s}$ are randomly distributed at intergranular and transgranular positions from the edge (shank and thread) to bulk (shank and thread) of the bolt. The image shown in Figure 9(a) is an overview of the bolt microstructure

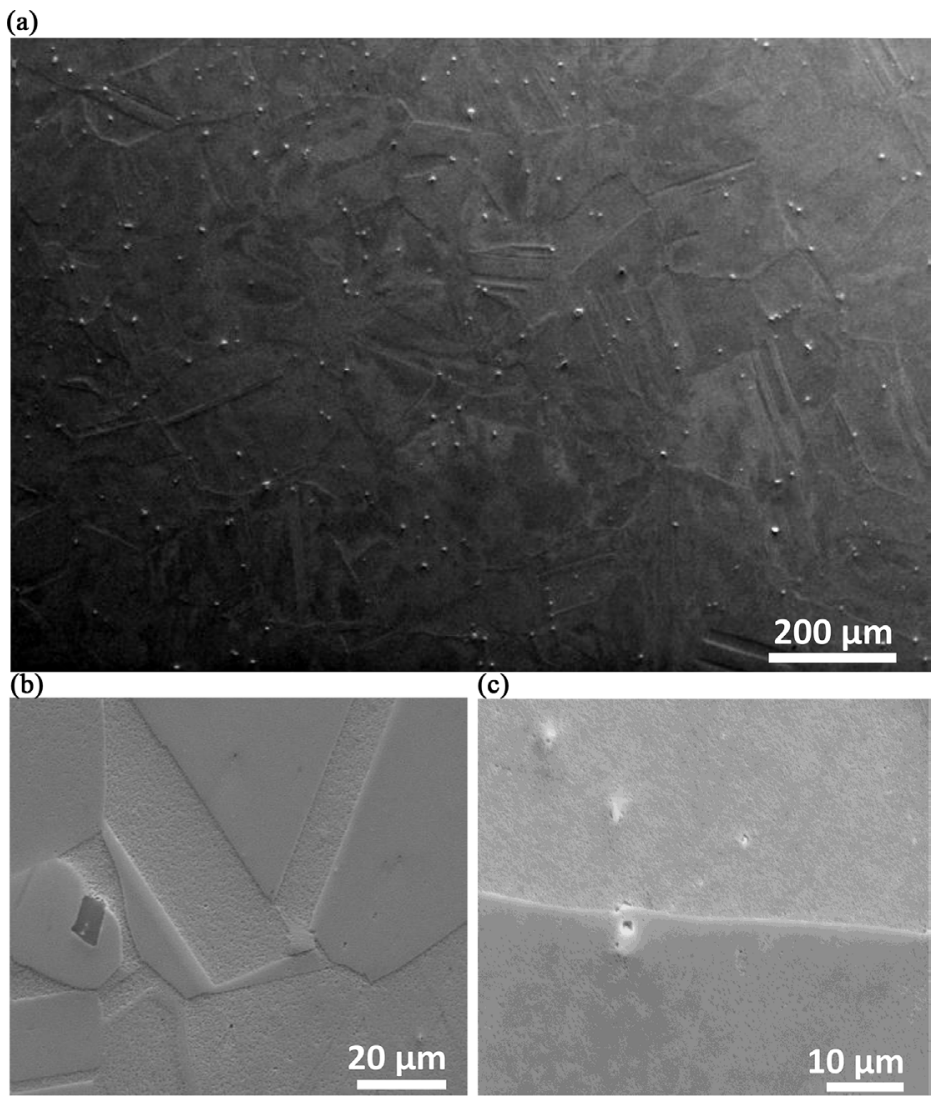

Figure 6. SEM images of specimen S3: (a) dark secondary electron image shows the random distribution of $\mathrm{M}(\mathrm{C}, \mathrm{N}) \mathrm{s}$ throughout the microstructure, which appear as bright spots. (b) and (c) show grain boundaries without second phase precipitation. 


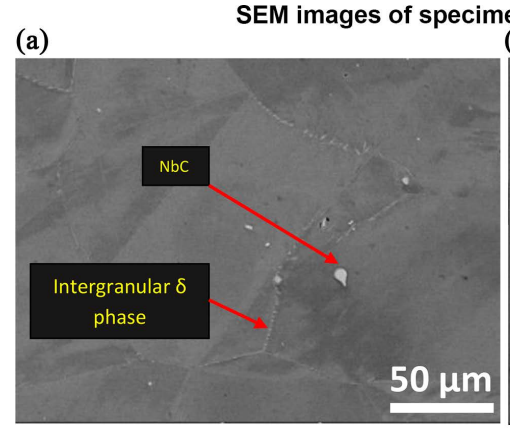

(a)

(c)

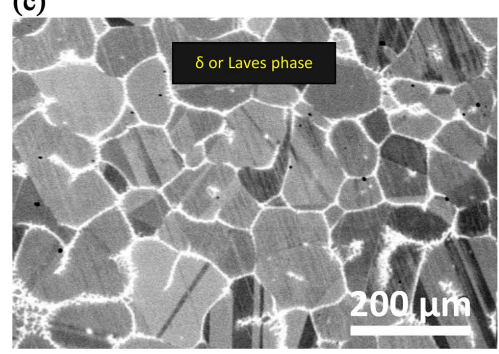

(b)

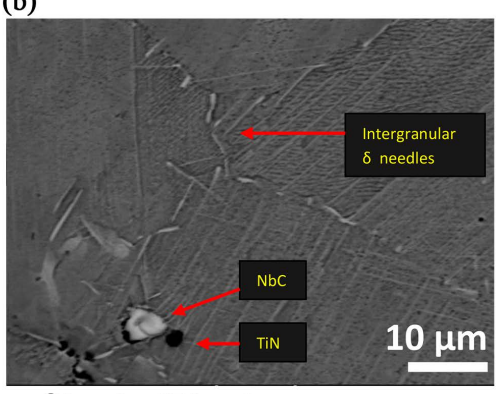

(d)

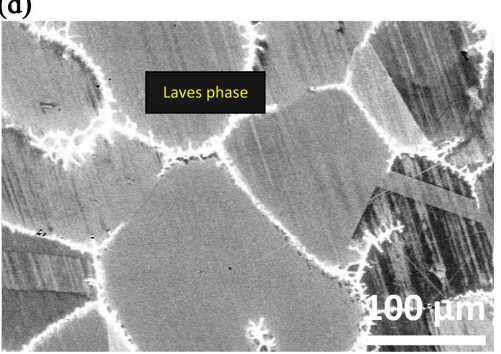

Figure 7. Typical SEM images of specimen S4 (under 16- and 25-h aging). (a) and (b) show the acicular delta phase (needle like) at grain boundaries extending to within grains because of 16-h aging. (c) and (d) show the continuous grain boundary Laves phase at 25 $\mathrm{h}$ of aging.

(a)

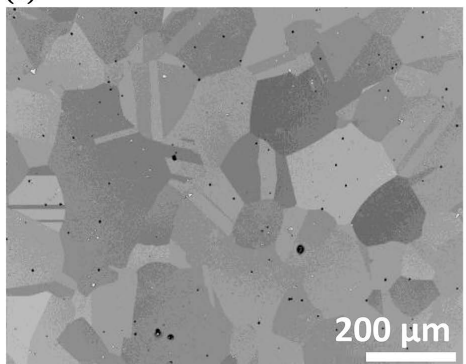

(c)

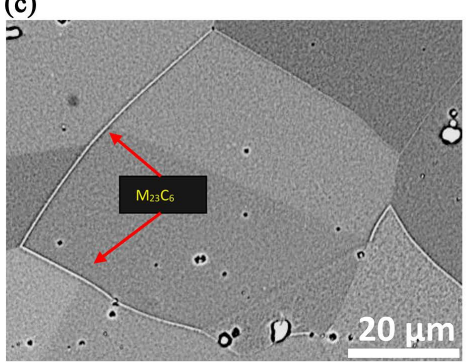

(b)

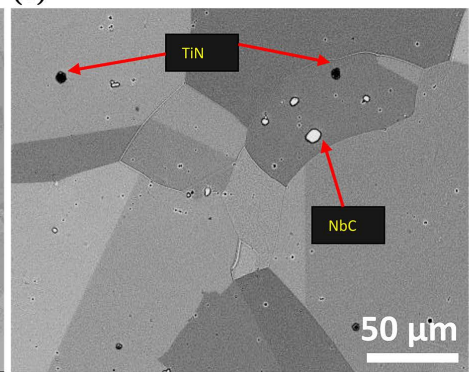

(d)

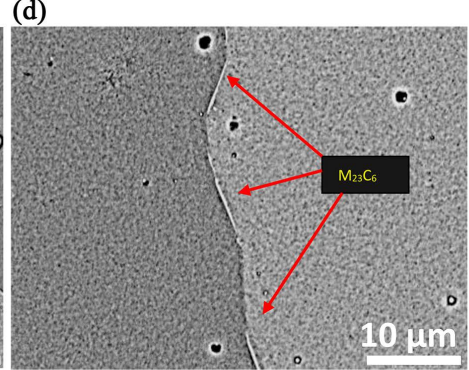

Figure 8. Typical SEM images of specimen S5 (a) showing the random distribution of M $(\mathrm{C}, \mathrm{N}) \mathrm{s}$ ( $\mathrm{NbC}$ and TiN) throughout the microstructure, which appear as black and white precipitates on grains and within grains. (c) and (d) show the discrete $\mathrm{M}_{23} \mathrm{C}_{6}$ precipitation at the grain boundary.

with $\mathrm{M}(\mathrm{C}, \mathrm{N}) \mathrm{s}$ precipitates (which appear as bright spots). They are present in the variable size range from 1 to $20 \mu \mathrm{m}$. They were seen at the shank edge, shank bulk, thread edge, and thread bulk of the bolt. Grain boundaries were carefully examined at each of these locations; it was determined that there was no discrete 
(a)

(b) Shank bulk of the API bolt

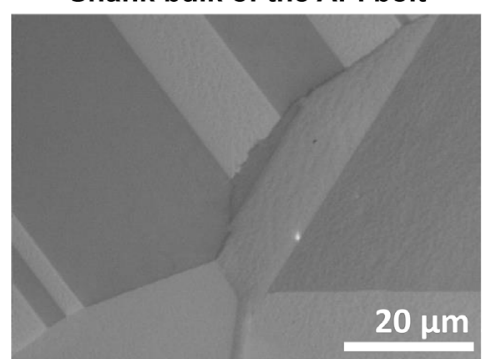

(d)

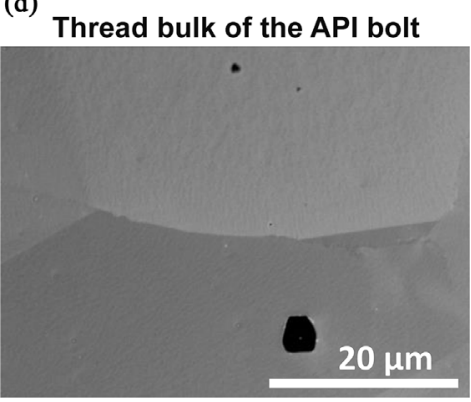

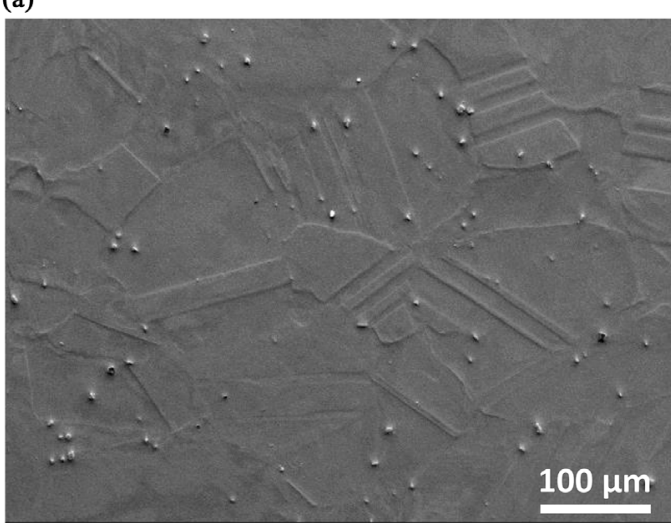

(c) Shank edge of the API bolt

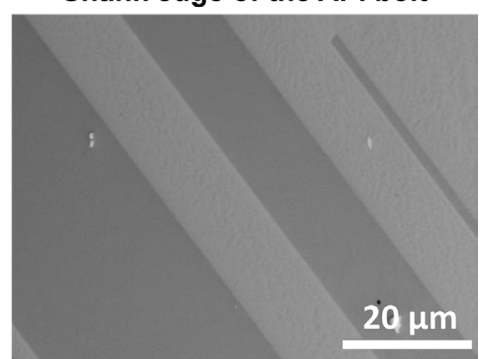

(e)

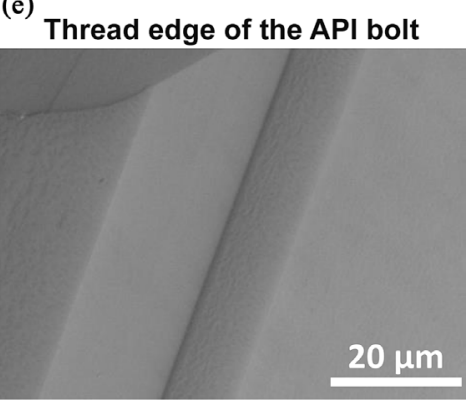

Figure 9. Typical SEM image (a) showing the random distribution of $M(C, N)$ s as bright particles from the bulk to the edge of the CRA bolt. SEM images (b)-(e) of S6 and S7 bolts showing twin boundaries and grain boundary triple junctions without intergranular precipitation at the shank bulk, shank subsurface, thread bulk, and thread subsurface.

or continuous intergranular precipitation, as shown in Figures 9(b)-(e).

\subsection{Transgranular Precipitates Morphology and Distribution: $\gamma^{\prime}$ and $\gamma^{\prime \prime}$}

The TEM images of specimens from the API bolt and RB are shown in Figures 10-17. The morphology (shape and size) of nanoprecipitates examined under TEM was compared with the established metallurgy of Inconel 718 [12] [19] [27] [34]. In addition to different morphology, each nanophase had a unique selected area diffraction pattern associated with its crystal structure, which were recorded as a confirmation of their existence in the fcc $\gamma$ matrix. The bright primary spots are related to fcc $\gamma$, and secondary faint spots are associated with $\gamma^{\prime}$. These faint spots, where they appear to be elongated, represent the $\gamma^{\prime \prime}$ phase. Furthermore, EDS line scans (length depending upon the nanophase size) were conducted 
from the $\gamma$ matrix to the nanophase to confirm phase composition.

Figure 10 shows the TEM images of solution-treated sample S1 from RB with the $\gamma^{\prime}$ precipitation of $<2 \mathrm{~nm}$. In the dark field imaging mode, Figure 10(a) shows the overview of the $\gamma$ matrix with the dense homogenous distribution of $\gamma^{\prime}$ precipitates. The electron-diffraction pattern at $(\overline{010})$, shown in Figure 10(b), is associated with the fcc $\gamma$ matrix because the size of the $\gamma^{\prime}$ precipitates is small and not easily distinguishable from that of the $\gamma$ matrix, as evident from Figure 10 (c), which shows a mottled appearance.

Sample $\mathrm{S}_{\mathrm{API}}$ has a dense homogenous distribution of spherical $10-20 \mathrm{~nm} \gamma^{\prime}$ precipitates. Typical TEM images from the bulk and edge (subsurface) of $S 2_{\mathrm{API}}$ are shown in Figures 11(a)-(c); Figure 11(b) is the high-magnification image of Figure 11(a). The electron-diffraction pattern at (001), shown in Figure 11(d), indicates the presence of the $\gamma^{\prime}$ phase. Few precipitates appeared to exceed the 20-nm barrier, which occurred because $\gamma^{\prime}$ precipitates coalesced to form elongated precipitates, Figure 11 (c). This observation agrees with the findings of Whitmore et al. [39] (for 718 plus billets, $2 \mathrm{~cm}$ in diameter and 2-cm long) where most of $\gamma^{\prime}$ precipitated after single aging (solution treatment at $975^{\circ} \mathrm{C}$ WQ then aging at $788^{\circ} \mathrm{C}$ for $4 \mathrm{~h} \mathrm{AC}$ ) were approximately $23.5 \mathrm{~nm}$ in diameter; however, after double aging (solution treatment at $975^{\circ} \mathrm{C}$ WQ then aging at $788^{\circ} \mathrm{C}$ for 4

(a)

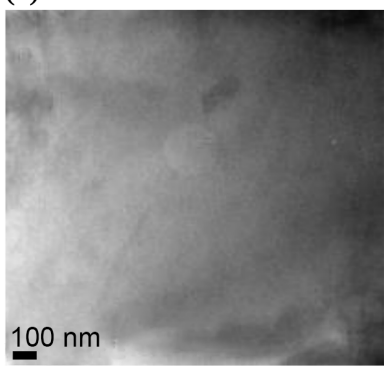

(b)

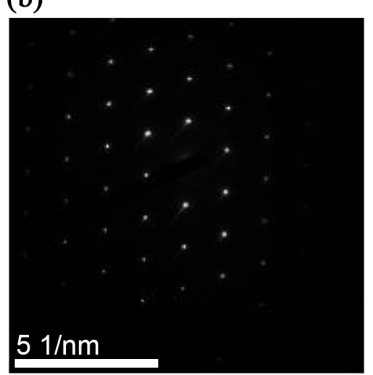

(c)

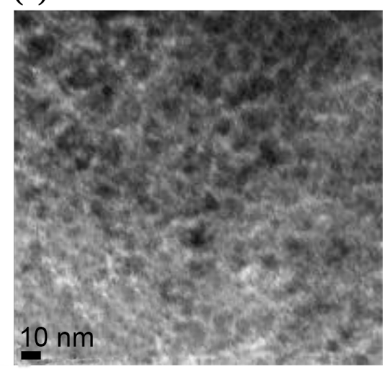

Figure 10. TEM image of S1 from RB at zone axis [011]. (a) shows an overview of the $\gamma$ matrix, whereas (b) shows the strong selected area diffraction pattern at $(0 \overline{00})$, which corresponds to the $\gamma$ matrix, and (c) is the dark field image, which was acquired at higher magnification and shows the mottled appearance of the $\gamma$ matrix.

(a)

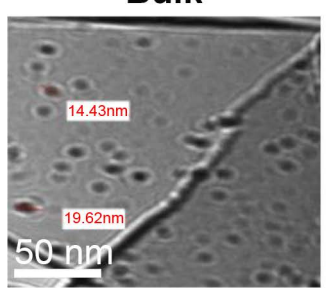

(b)

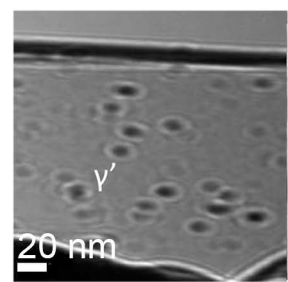

(c)

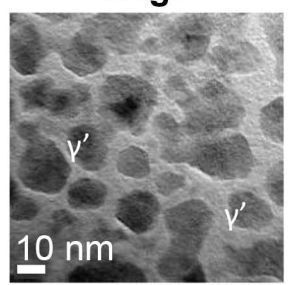

(d)

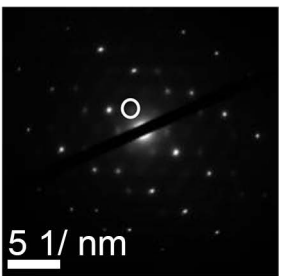

Figure 11. Typical TEM images of S2 API from the bulk and edge: (a) Bulk-at zone axis [10 $\overline{1}$ ], showing the overview of $\gamma^{\prime}$ precipitates homogenously distributed throughout the matrix. The image in (b) is the high magnification of (a) and shows $\gamma^{\prime}$ precipitates of $10-20 \mathrm{~nm}$. (c) Edge-at zone axis [02 $\overline{1}$ ], showing $\gamma^{\prime}$ precipitates of approximately $10-20 \mathrm{~nm}$. (d) Strong selected area diffraction pattern spots at (001) related to $\gamma^{\prime}$ precipitates and $\gamma$ matrix. 
h, WQ to RT then $675^{\circ} \mathrm{C}$ for $8 \mathrm{~h} \mathrm{AC}$ ), they were $14 \%$ larger, i.e., $28.0 \mathrm{~nm}$ in diameter. After double aging, the physical definition of $\gamma^{\prime}$ precipitates was enhanced compared to that after single aging, which has been also reported in [20]. However, S5 under double aging produced an additional population of $\gamma^{\prime}$ precipitates of 1 - $10 \mathrm{~nm}$ along with primary $\gamma^{\prime}$ and $\gamma^{\prime \prime}$ populations, as shown in Figure 14(c) and Figure 14(d). Compared to the single population of $\gamma^{\prime}$ in S2 $\mathrm{API}$, Ding [40] observed two main populations in the RB of 718 that was solution-treated at $1050^{\circ} \mathrm{C}$ for $1 \mathrm{~h} \mathrm{AC}$ but was double-aged at $720^{\circ} \mathrm{C}$ for $8 \mathrm{~h}$ and $650^{\circ} \mathrm{C}$ for $8 \mathrm{~h}$. They have reported the presence of primary $\gamma^{\prime}$ of $25 \mathrm{~nm}$, which was homogeneously distributed throughout the matrix, and secondary $\gamma^{\prime}$ of 100 nm, which had a much lower density.

The TEM image of sample S3 in Figure 12(a) is a dark field image, where the $\gamma^{\prime}$ phase is not easily distinguishable from the $\gamma$ matrix of sample $\mathrm{S} 3$, which is non-standard solution-treated at $1250^{\circ} \mathrm{C}$ for $2 \mathrm{~h}$ followed by water quenching. As expected, electron-diffraction pattern at $(\overline{110})$ in Figure $12(\mathrm{~b})$ is more related to the $\gamma$ matrix, which is evident from the distinct primary spots. S3 was non-standard solution-treated to verify whether providing higher $\mathrm{Nb}$ back to the $\gamma$ matrix leads to the formation of $\gamma^{\prime \prime}$ metastable or intergranular stable $\delta$ phases in $\mathrm{S} 4$ samples (which are solution-treated at $1250^{\circ} \mathrm{C}$ followed by two aging treatments for 16 and $25 \mathrm{~h}$ ). The image in Figure 13(a) was acquired in the bright field imaging mode, where the $\gamma^{\prime}$ precipitates (closely spaced) grew under $16 \mathrm{~h}$ of aging and were homogenously distributed throughout the matrix. The high-magnification image in Figure 13(c) shows a dark faint line around the precipitates, which differentiates $\gamma^{\prime}$ from the $\gamma$ matrix, and spherical-to-spheroid-shaped $\gamma^{\prime}$ precipitates in the range of $10-50 \mathrm{~nm}$ with a bulge effect. Whereas, during the 25 -h aging process, few $\gamma^{\prime}$ precipitated during the aging process because there was an insufficient amount of $\mathrm{Ti}$ and $\mathrm{Nb}$ in the $\gamma$ matrix for $\gamma^{\prime}$ precipitation. Figure 13(d) shows that $\gamma^{\prime}$ precipitates are widespread with greater inter-particle spacing $(>200 \mathrm{~nm})$; the maximum size of $\gamma^{\prime}$ was

(a)

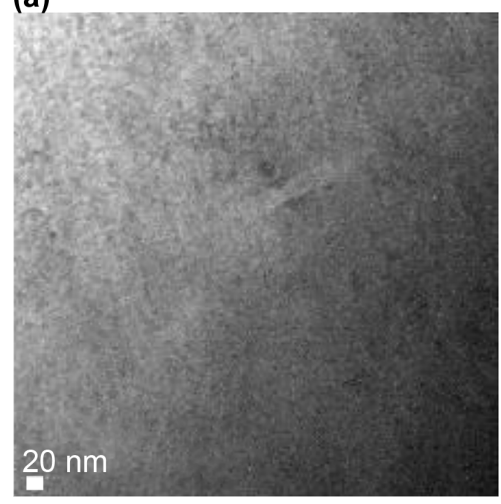

(b)

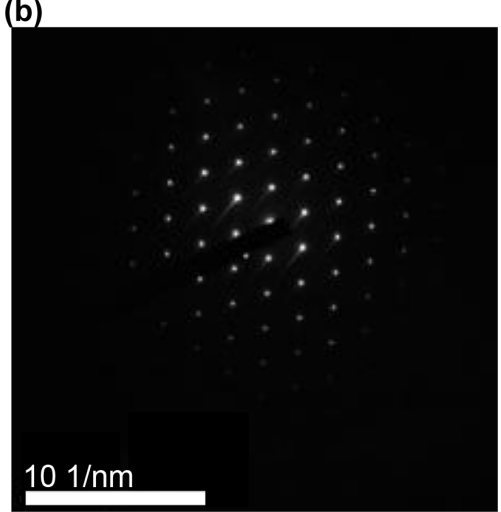

Figure 12. TEM image of S3 (a) at zone axis [ $\overline{131}$ ] showing mottled appearance of densely distributed very small $\gamma^{\prime}$ precipitates of approximately $1-2 \mathrm{~nm}$. (b) Selected area diffraction pattern at $(\overline{110})$ indicates the greater amount of the fcc $\gamma$ matrix than that of $\gamma^{\prime}$ 
(a)

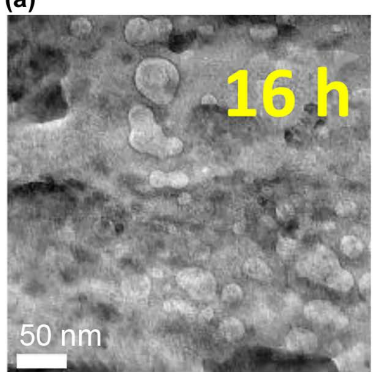

(d)

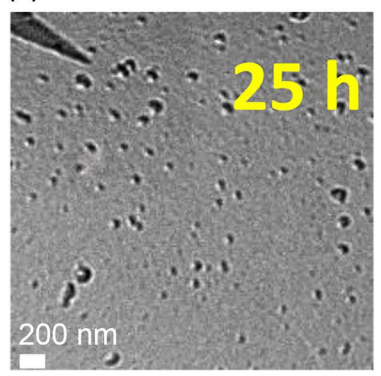

(b)

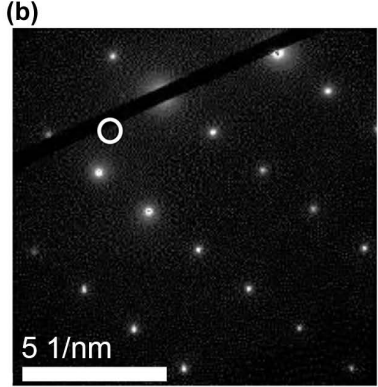

(e)

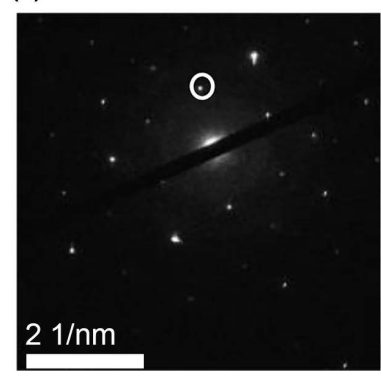

(c)

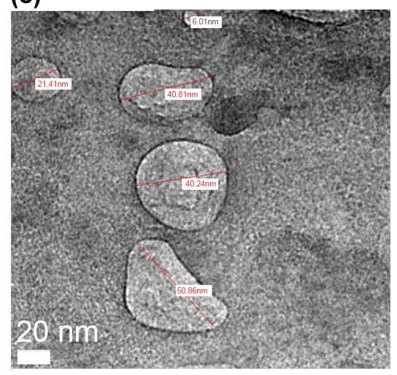

(f)

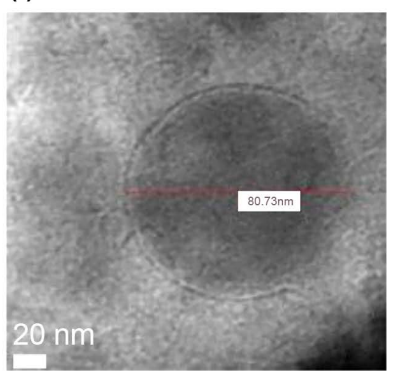

Figure 13. TEM images of sample S4, $16 \mathrm{~h}$ (a)-(c) at zone axis [ $\overline{100} 0$ and $25 \mathrm{~h}(\mathrm{~d})$-(f) at zone axis [ $\overline{103}$ ] from RB: (a) is a Bright field image showing the overview of spherical and spheroidal $\gamma^{\prime}$ precipitates that are homogenously distributed throughout the $\gamma$ matrix with some coalescence of $\gamma^{\prime}$ into aggregates in the range of $10-50 \mathrm{~nm}$. (b) Strong selected area diffraction pattern associated with $\gamma^{\prime}$ and $\gamma$ matrix at $(\overline{01})$. Panel (c) shows higher magnification. Panel (d) shows random $\gamma^{\prime}$ precipitation with large inter-particle spacing. (e) Strong selected area diffraction spots associated with $\gamma^{\prime}$ and $\gamma$ matrix at $(0 \overline{12})$. Panel (f) is the higher magnification, which shows the maximum size of the $\gamma^{\prime}$ precipitate of approximately $80 \mathrm{~nm}$.

determined to be approximately $80 \mathrm{~nm}$, as evident from Figure 13(f). The strong electron-diffraction patterns, which confirmed the presence of $\gamma^{\prime}$ in S4 samples after aging for 16 and $25 \mathrm{~h}$, are attributed to $(\overline{101})$ and $(0 \overline{012})$, respectively, and are shown in Figure 13(b) and Figure 13(e).

Sample S5 after the double aging heat treatment has a homogeneous distribution of $\gamma^{\prime}$ and $\gamma^{\prime \prime}$ (from bulk to subsurface), as shown in the overview TEM image in Figure 14(a). The size of $\gamma^{\prime}$ precipitates was approximately $50 \mathrm{~nm}$ in diameter, and $\gamma^{\prime \prime}$ appeared as elongated disks of $50-70 \mathrm{~nm}$. The selected area diffraction pattern shown in Figure 14(b) strongly corresponds to both $\gamma^{\prime}$ and $\gamma^{\prime \prime}$ phases at $(\overline{10})$. In the bright field imaging mode, small secondary $\gamma^{\prime}$ precipitates of 1 - $10 \mathrm{~nm}$ were also observed between the primary $\gamma^{\prime}$ and $\gamma^{\prime \prime}$, as evident from the pointed red arrows in Figure 14(c) and Figure 14(d). These precipitates likely appeared during air cooling to RT after the final aging at $621^{\circ} \mathrm{C}$ for $8 \mathrm{~h}$. Furthermore, a faint dark line appeared around these precipitates, which may be associated with the lattice misfit between $\gamma$ and $\gamma^{\prime}$. Upon closer inspection (see Figure 14(c) and Figure 14(d)], the small $\gamma^{\prime}$ precipitates appeared to have a faceted growth with edge definition, which differs from large $\gamma^{\prime}$ precipitates that have a dark appearance. This morphological difference may have a profound effect on the strength of the alloy. Large $\gamma^{\prime}$ appears to consist of spheres and 
(a)

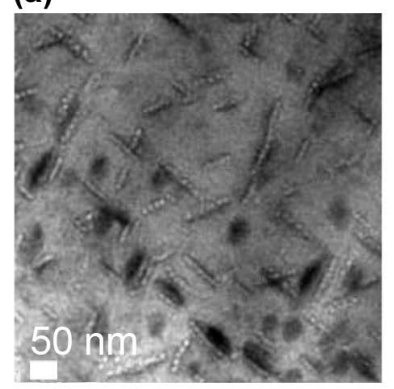

(c)

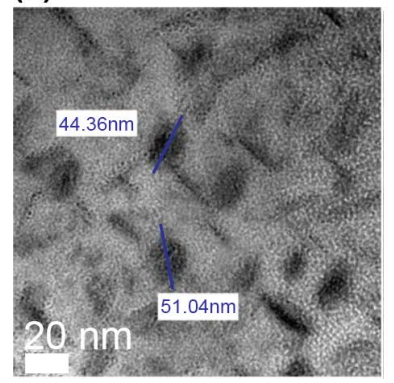

(b)

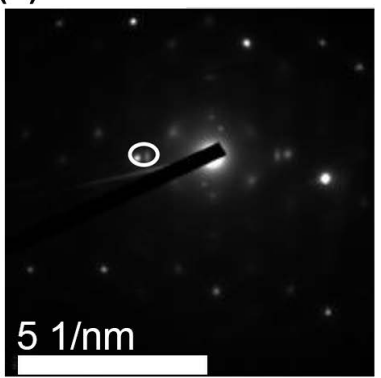

(d)

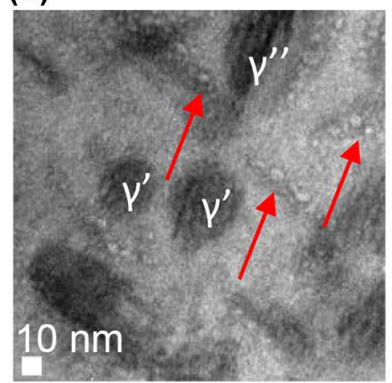

Figure 14. Typical TEM images of S5 showing (a) (zone axis [12 11$]$ ) the maximum $\gamma^{\prime}$ precipitate of approximately $50 \mathrm{~nm}$ in diameter and $\gamma^{\prime \prime}$ as elongated disks of $50-70 \mathrm{~nm}$. (b) Selected area diffraction pattern corresponding to the $\gamma$ matrix, and $\gamma^{\prime}$ and $\gamma^{\prime \prime}$ phases. (c) and (d) show higher magnification-where small secondary $\gamma^{\prime}$ precipitates of $110 \mathrm{~nm}$ (red arrows) are observed around the primary $\gamma^{\prime}$ precipitates.

spheroids and is coalesced at some points, whereas small $\gamma^{\prime}$, which is observed in dark field mode, is much more distinct than large $\gamma^{\prime}$, which appears to be embedded along with $\gamma^{\prime \prime}$ within the $\gamma$ matrix.

The TEM image in Figure 15(a) shows the typical nanostructures of the shank bulk area of the bolt (S6 and S7), i.e., $\gamma^{\prime}$ precipitates and few random $\gamma^{\prime \prime}$. At higher magnification [Figure 15(b)] in the dark field mode, the $\gamma^{\prime}$ phase appears to consist of spheres and spheroids and is coalesced (appearing elongated) as approximately $20-30-\mathrm{nm}$ black precipitates. The selected area diffraction patterns strongly correspond to the presence of the $\gamma^{\prime}$ phase at (100) [see Figure 15(c) and $\gamma^{\prime \prime}$ at $\left(\overline{1} 0 \overline{1}\right.$ ) (see Figure 15(f)) ]. However, for S2 $2_{\mathrm{API}}$ and $\mathrm{S} 4, \gamma^{\prime}$, which is observed in the dark field mode for S6 and S7, is considerably less clear and appears to be embedded within the $\gamma$ matrix. However, $\gamma^{\prime \prime}$ at the shank edge, see Figure 15(d) and Figure 15(e), precipitated with a morphology that is similar to that in sample S5 from RB. Similarly, for the thread bulk, the nanostructure shown in Figure 16(a) and Figure 16(b) shows the precipitation of $\gamma^{\prime}$ and $\gamma^{\prime \prime}$. However, unlike the nanostructure of the shank edge, the thread edge is made of both 50-nm $\gamma^{\prime}$ and $50-100-\mathrm{nm} \gamma^{\prime \prime}$, as seen in Figure 16(d) and Figure 16(e). To substantiate the existence and morphology of $\gamma^{\prime}$ and $\gamma^{\prime \prime}$ phases, TEM images were randomly extracted from similar locations on other bolt samples (S6 and S7), as shown in Figure 17. The results were identical to what was observed earlier, except for some sheared 50-nm $\gamma^{\prime}$ precipitates and $>100 \mathrm{~nm} \gamma^{\prime \prime}$, at the thread and shank edge (subsurface). 
(a)

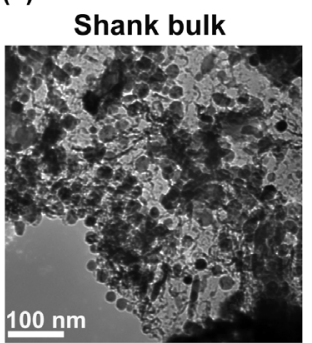

(d)

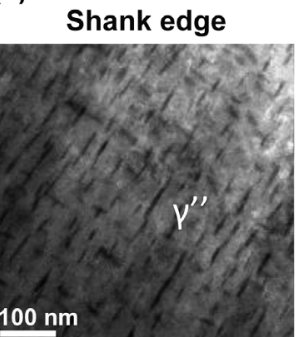

(b)

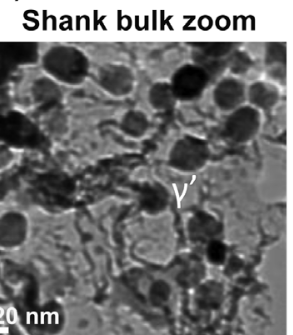

(e)

Shank edge zoom

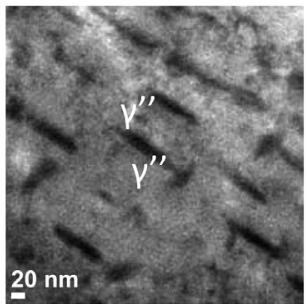

(c)

DP Shank bulk

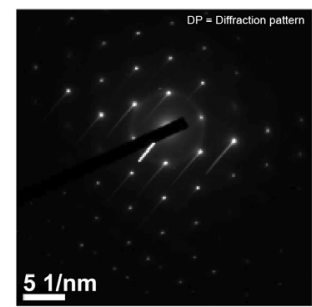

(f)

DP Shank edge

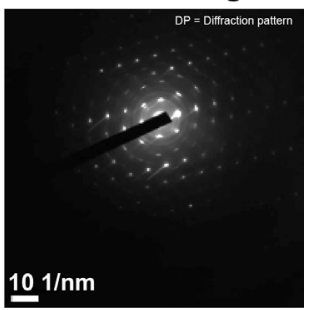

Figure 15. Typical TEM images of API bolt (S6 and S7) from shank bulk (a) and (b) at zone axis [ $0 \overline{11}$ ], and from shank edge (c) and (d) at zone axis [ $\overline{101}$ ]. (a) Dark field imaging-overview of $\gamma^{\prime}$ precipitates appearing as 20 - 30-nm black spheres and few 30 50-nm elongated disk-shaped $\gamma^{\prime \prime}$ in the $\gamma$ matrix. Panel (b) is the higher magnification of (a), which clearly shows that $\gamma^{\prime}$ has a 30-nm spherical shape. Panel (c) shows the selected area diffraction pattern, which corresponds to $\gamma^{\prime}$ at (100). Panel (d) shows the shank edge where $50-100-\mathrm{nm} \gamma^{\prime \prime}$ precipitated as elongated disks, and panel (e) is the higher magnification of (d). Whereas, (f) shows strong diffraction spots associated with the $\gamma^{\prime \prime}$ phase at the $(\overline{1} 0 \overline{1})$ shank edge of the bolt.
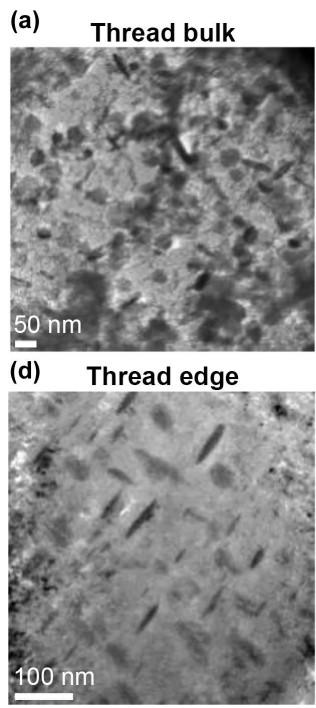

(b) Thread bulk zoom

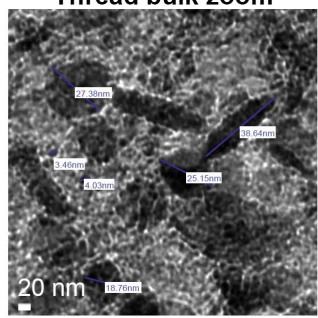

(e) Thread edge zoom

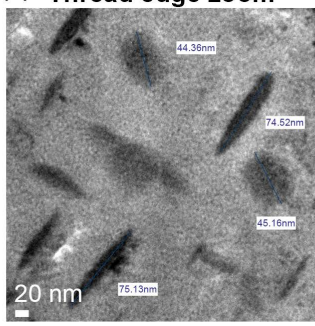

(c) DP Thread bulk

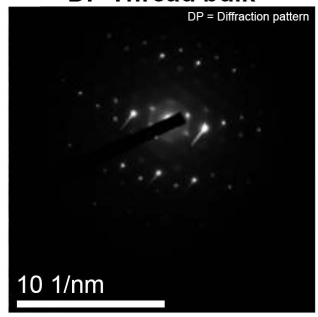

(f) DP Thread edge

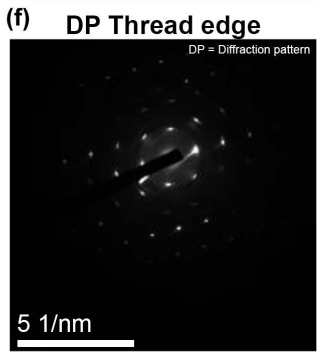

Figure 16. Typical TEM images of API bolt (S6 and S7) from the thread bulk (a) and (b) at zone axis [ $\overline{121}$ ] and from the thread edge (d) and (e) at zone axis [ $\overline{110}$ ]. Panel (a) shows the overview of $30-\mathrm{nm} \gamma^{\prime}$ precipitates, which appear as black spheres, and few 50-nm elongated disk-shaped $\gamma^{\prime \prime}$ that are randomly distributed throughout the $\gamma$ matrix. Panel (b) shows the higher magnification of (a). Panel (d) shows the overview of the structure at the thread edge, and the high-magnification image in panel (e) show $\gamma^{\prime}$ with a 50-nm spherical shape and $50-100-\mathrm{nm} \gamma^{\prime \prime}$. Diffraction spots corresponding to $\gamma^{\prime}$ and $\gamma^{\prime \prime}$ phases, (c) at (011) and (f) at (112), for thread bulk and thread edge, respectively. 


\subsection{In-Air Tensile and Hardness Data}

Table 3 shows the strength data obtained for each specimen from in-air tensile

(a) Shank bulk

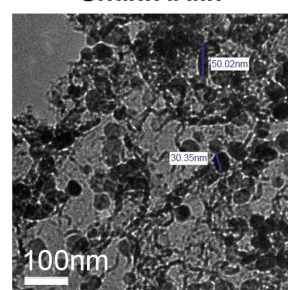

(e) Thread bulk

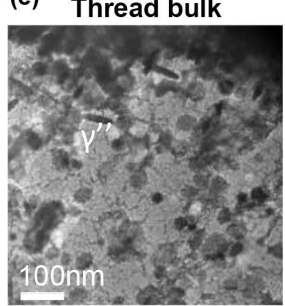

(b) DP Shank bulk

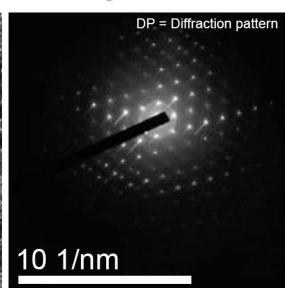

(f) DP Thread bulk (c) Shank edge

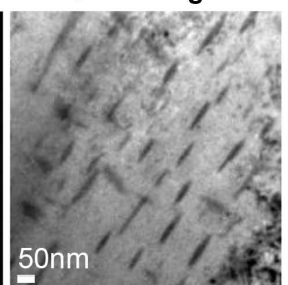

(g) Thread edge (d) DP Shank bulk

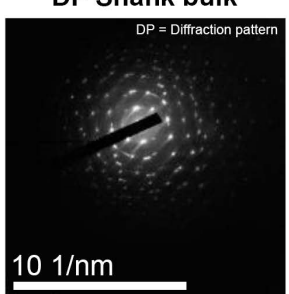

(h) DP Thread edge
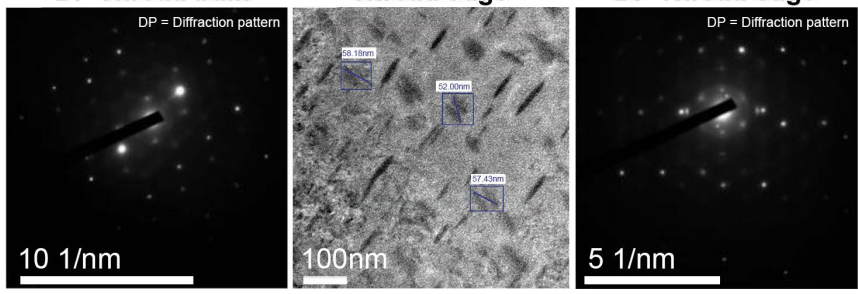

Figure 17. Random TEM images of the bolt (S6 and S7) from the shank bulk [ $\overline{113}$ ], shank edge [ $\overline{100}$ ], thread bulk [ $\overline{111}$ ] and thread edge [ $0 \overline{12}]$. (a) Shank bulk dark field image showing 30-nm $\gamma^{\prime}$ precipitates as black spheres and few 50-nm elongated disk-shaped $\gamma^{\prime \prime}$, which are randomly distributed throughout the $\gamma$ matrix. Panel (b) shows diffraction spots at (121), which are associated with $\gamma^{\prime}$. (c) Shank edge showing few $\gamma^{\prime}$ of approximately $50 \mathrm{~nm}$ and $\gamma^{\prime \prime}$ of $50-100 \mathrm{~nm}$ with (d) diffraction spots related to $\gamma^{\prime \prime}$ at (100). Panel (e) shows the thread bulk (similar to shank bulk) with $\gamma^{\prime}$ precipitates of approximately $30 \mathrm{~nm}$ and $\gamma^{\prime \prime}$ of approximately $50 \mathrm{~nm}$. Whereas, (g) shows the thread edge with sheared $\gamma^{\prime}$ precipitates of approximately $50 \mathrm{~nm}$ and $\gamma^{\prime \prime}$ in the range of $50-100 \mathrm{~nm}$. Panel (f) and (h) are the diffraction spots that correspond to the $\gamma$ matrix, $\gamma^{\prime}$ and $\gamma^{\prime \prime}$ phase at the thread bulk ( $0 \overline{10})$ and thread edge (001), respectively.

Table 3. Mechanical properties of the 718 alloy as rectangular billet and bolt

\begin{tabular}{cccccc}
\hline Specimen & бYS MPa & $\begin{array}{c}\sigma_{\text {YS MPa }} \\
(0.2 \% \text { Offset })\end{array}$ & $\begin{array}{c}\text { UTS } \\
(\mathrm{MPa})\end{array}$ & $\%$ RA & Vickers Hardness (HV) \\
\hline S1 RB & 350 & 360 & 700 & 67.7 & $158 \pm 5$ HV10 \\
S2 RB & 840 & 880 & 1240 & 50.8 & $340 \pm 2$ HV10 \\
S3 RB & 280 & 290 & 550 & 64.1 & $185 \pm 10$ HV10 \\
S4 RB 16 h & 680 & 700 & 860 & 55.3 & $258 \pm 10$ HV10 \\
S4 RB 25 h & 475 & 490 & 560 & 66.7 & $223 \pm 10$ HV10 \\
S5 RB & 910 & 920 & 1150 & 49.1 & $408 \pm 5$ HV05 \\
S6 Bolt & 880 & 920 & 1170 & 41.4 & $370 \pm 2$ HV10 (Bulk) \\
& & & & - & $400 \pm 5$ HV10 (Edge) \\
S7 AR Bolt & 880 & 920 & 1175 & 42.9 & $370 \pm 2$ HV10 (Bulk) \\
\end{tabular}

Table 3 Mechanical data on solution-treated and aged specimens of alloy 718 in the form of rectangular

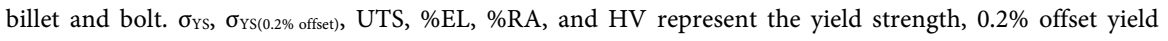
strength, ultimate tensile strength, percentage reduction of area, and average Vickers hardness for each specimen, respectively. Note: The values of $\sigma_{\mathrm{YS}}, \sigma_{\mathrm{YS}(0.2 \% \text { offset })}$ UTS, \%EL, and \%RA for S6 and AR Bolts obtained from tensile specimens represent the bulk of the of bolt and not the edge (subsurface). 
tests. The tensile specimens were extracted from the bulk of RB and bolt. Each heat-treated specimen, as shown in Table 2, has two tensile specimens for mechanical characterization. Thus, two measurements for yield strength, ultimate tensile strength, and percentage reduction in area were calculated from the tested tensile specimens, and the readings were averaged. The tensile specimens were machined from the bulk of the bolt (S6 and S7); therefore, the tensile property data does not relate to the microstructure at the periphery or the edge of the bolt. Whereas, the hardness data from the outer periphery (close to the surface, approximately $10 \mu \mathrm{m}$ ) compared to that from the bulk of the bolt has the difference of $\Delta 30 \mathrm{HV}$. Thus, FIB samples were extracted and analyzed by TEM to perform detailed structural investigation. The in-air \%RA values of 718 variants will help to observe the PLC effect at subsea temperatures under CP.

\section{Discussion}

Figures 4-9 show primary MC-type carbides (NbC) and MN-type nitrides (TiN). They are observed in the entire microstructure of the bolt (from the bulk to the edge of the shank and thread) RB specimens at intergranular and transgranular regions both under solution-treated and aging conditions. There was no considerable change observed in the size and volume fraction of primary carbides and nitrides. At any given location in each specimen, the size range of 1-30 $\mu \mathrm{m}$ and the volume fraction of carbides and nitrides are comparable; any slight difference may be due to the difference in heating parameters. The reason for choosing the non-standard solution treatment is to have the low volume fraction of $\mathrm{M}(\mathrm{C}, \mathrm{N}) \mathrm{s}$ in the $\gamma$ matrix by dissolving $\mathrm{NbC}$ and TiN back into the $\gamma$ lattice, which increases the grain size compared to those of S1 and S2. Thus S3 and S4 (16-h and 25-h aging) are the essential 718 variants for assessing the MCN susceptibility to HE under slow strain rate testing. Sims et al. [27] have reported that the low volume fraction of carbides and nitrides (approximately $<2 \%$ ) with heterogeneous distribution at transgranular and intergranular positions do not considerably affect the mechanical properties (yield strength and hardness) of superalloys. The grain size is critical to the strength of the alloy 718 bolt; specifically, excessively fine grains decrease rupture strength, whereas excessively large grains have lower tensile strength. Grain size can be controlled by primary carbides and nitrides because they pin grain boundaries and inhibit grain growth. However, these particles are the potential source of hydrogen traps; in Inconel 718, $77-87 \mathrm{~kJ} / \mathrm{mol}$ has been suggested as the activation energy for hydrogen atoms to be trapped in carbide particles [41].

The activation energy of $58 \mathrm{~kJ} / \mathrm{mol}$ has been proposed as the criterion to determine whether hydrogen, which is already trapped in a site, can be reversibly released or not [42]. However, hydrogen-assisted intergranular cracking is more common in $\delta$ decorated grain boundaries [17] [18] [29] [30] (specimen S2 had discrete, and $\mathrm{S} 4$ treated for $16 \mathrm{~h}$ had continuous $\delta$ platelets extending to grains, see Figure 5(c) and Figure 7(b)). The hydrogen binding energy to $\delta$ particles is 
$30 \mathrm{~kJ} / \mathrm{mol}$, which is smaller than $58 \mathrm{~kJ} / \mathrm{mol}$ [40]. To compare $\delta$ and $\gamma^{\prime \prime}$, Dai and Liu [43] have used the first principles total energy pseudo-potential method that is based on the density functional theory to determine that both $\gamma^{\prime \prime}$ and $\delta$ have covalent bonding between $\mathrm{Ni}-\mathrm{Ni}$ atoms and the combination of covalent and ionic bonding between $\mathrm{Ni}$ and $\mathrm{Nb}$ atoms. There is covalent bonding between $\mathrm{Nb}$ and $\mathrm{Nb}$ atoms in the $\gamma^{\prime \prime}$ phase, and no interaction was observed between $\mathrm{Nb}$ and $\mathrm{Nb}$ atoms in the $\delta$ phase. In addition, their results have indicated that both phases are hard and have good ductility. The bulk moduli of $\gamma^{\prime \prime}$ and $\delta$ are 211 $\mathrm{GPa}$ and $208 \mathrm{GPa}$, respectively, which make both phases incompressible and hard. Thus, except from providing remarkable strength to the subsea bolt, the exact effect of metastable $\gamma^{\prime \prime}$ on HE surface cracking remains unclear. However, solution-annealed specimens S1 and S3 only contain MCN particles, and Rezende et al. [8] have reported that for solution-annealed specimens, the HE impact was less pronounced with an increase in the strength compare to that of the aged specimens (with $\gamma^{\prime \prime}$ ). It can still be argued that the presence of MCN at grain boundaries and within grains [17] [44] (at intersection of DSLs) is critical to HE, and additional studies are needed to clarify the exact mechanism of MCN particles on the HE of bolt. To observe the sole effect of $M(C, N) s$ with regard to the PLC (under hydrogen charging and slow strain rate testing) study in the future, 718 variants of S1 and S3 were added and microstructurally characterized, as shown in Figure 4, Figure 6, Figure 10, and Figure 12. Similarly, S4 (16-h and 25-h aging) was added to have $\delta$ and Laves at intergranular sites and greater inter-particle spacing for transgranular $\gamma^{\prime}$ precipitates, as seen in Figure 7 and Figure 13, respectively.

In this study, twin boundaries were also observed for all 718 variants, including bolt specimens S6 and S7, as seen in Figure 9. Some researchers have reported [45] [46] that twin boundaries are considered to have low hydrogen solubility and high separation energy, which makes them less susceptible to HE. Whereas, Seita et al. [47] have reported that for Inconel 725, crack initiation is associated with twin boundaries but at the same time is more resistant to crack propagation. However, Zhang et al. [15] have not observed crack initiation and propagation in Inconel 718. Further analysis revealed that crack path is always along the $\{111\}$ crystallographic plane, which is also the plane of DSLs. Grain boundary triple junctions assist decohesion and crack initiation at grain boundary and particle interface, which has been also reported by Tarzimoghadam et al. [16]. Triple junctions were observed in all specimens, including subsea bolt specimens (see Figure 3 for details). However, bolt grain boundaries were observed to lack any discrete intergranular precipitates, which is evident from Figure 9. However, under identical API aging, S2 (from RB) was observed to have discrete intergranular $\delta$. This occurs because $\mathrm{Nb}$ was consumed to form stable $\mathrm{Ni}_{3} \mathrm{Nb}$ in $\mathrm{S} 2$ and metastable $\mathrm{Ni}_{3} \mathrm{Nb}$ in bolt specimens ( $\mathrm{S} 6$ and $\mathrm{S} 7$ ) at bulk and edge regions. This occurs because the extensive cold work, which the bolt underwent, and then under API aging, sluggish kinetics cause preferential $\gamma^{\prime \prime}$ preci- 
pitation, see Figure 15(d) and Figure 17(c). It is clear from the bolt microstructure that there is a morphological gradient of the second phase from the bulk to the edge; specifically, 30-nm $\gamma^{\prime}$ and 30 - 50-nm $\gamma^{\prime \prime}$ observed in the bulk, 50-nm $\gamma^{\prime}$ and $50-100-\mathrm{nm} \gamma^{\prime \prime}$ are observed at the edge. Whereas, the nearly consistent morphology for the second phase (from bulk and edge) was observed for 718 specimens extracted from RB, apart from specimen S5, where the second $\gamma^{\prime}$ population of $1-10 \mathrm{~nm}$ exist along with primary 50-nm $\gamma^{\prime}$ and $50-70-\mathrm{nm} \gamma^{\prime \prime}$, as seen in Figure 11, Figure 13, and Figure 14, which also contributed to its remarkable strength $(910 \mathrm{MPa})$ and hardness $(408 \mathrm{HV})$, as seen in Table 3.

To replicate the nanostructure of the AR subsea S7 bolts (from the bulk and the surface/subsurface), S6 bolts underwent the cold rolling of the shank and threads after the API heat treatment. Irrespective of the use of S7 bolts under CP, TEM examination confirmed (see Figures 15-17) that both bolts have the same nanostructure at the bulk and surface (shank and thread) regions. Sheared and elongated $(>100 \mathrm{~nm}) \gamma^{\prime}$ and $\gamma^{\prime \prime}$ precipitates were observed, respectively, at the subsurface ( $\sim 10 \mu \mathrm{m}$ from the surface) of the thread and shank regions, as shown in Figure 17(c) and Figure 17(g). It has been reported by various researchers [8] [28] [29] [35] [44] [48] while assessing HE susceptibility of alloy 718 that under hydrogen charging, surface cracks begin to appear even without any loading. Lu et al. have reported [44] for alloy 718 that transgranular surface and subsurface cracks considerably increase between $80 \mathrm{~h}$ and $120 \mathrm{~h}$ of hydrogen charging; they have concluded that surface cracks induced by hydrogen charging led to the formation and propagation of transgranular cracks under loading. This observation is supported by Li et al. [49] who have not observed surface cracks on 718 tensile samples that were hydrogen-charged for $2 \mathrm{~h}$. Thus, it is the time-dependent process, where hydrogen evolving from $\mathrm{CP}$ penetrates at least to the subsurface region of the subsea bolt. We know that the concentration gradient of hydrogen (evolving from $\mathrm{CP}$ ) varies from the surface to bulk $\gamma$ lattice, and the operating service stress for bolts sometimes exceeds $70 \%$ of the yield strength. However, the intersection of DSLs [15] [16] [17] during loading acts on high stress-concentrated regions (sheared nanoprecipitates), where hydrogen accumulates and forms embryos of nanovoids at transgranular regions. Therefore, the degree of $\mathrm{HE}$ is more pronounced close to the surface/subsurface of the 718 alloy [8] [15] [16] [17] [28] [29] [35] [44] [48] [49] and exhibits brittle fracture. Thus, the transition region is brittle to ductile and is least effected by the HE ductile region at the bulk. However, the nanostructure responsible for brittle transgranular cracking close to the surface is still not-extensively studied.

The role of DSLs close to the surface is well established [15] [16] [17] in hydrogen-assisted cracking for alloy 718; however, the primary nanoprecipitates responsible for surface and subsurface cracking remain unknown and need to be studied. The nanostructure at the surface cracks has not been extensively reported (including the morphology-shape and size), and only generic nanophases representing the bulk of the tensile samples are accounted for. This is the 
reason why the manufacturing route of the bolt is critical and determines the nanostructure at the extreme surface/subsurface of the alloy 718. By analogy, it has been reported [44] [49] that the machining of the tensile specimens (for hydrogen charging and slow strain rate testing) has been always performed after the heat treatment, which have resulted in different nanostructure at the surface/subsurface of the tensile specimens in comparison to that of the bulk lattice; both the number density and the length density of surface/subsurface cracks depend on the hydrogen charging time (mentioned earlier). Whereas, in the current study, the detailed examination of the outer periphery (surface) of the used subsea bolt (S7) (at thread and shank regions) revealed the Vickers hardness of $400 \mathrm{HV}$ at the subsurface ( $370 \mathrm{HV}$ at bulk) of the bolt, as shown in Table 3. FIB samples were lift-out from the sub-microstructure (approximately $10 \mu \mathrm{m}$ from the surface) of the shank and thread region. The schematic of the location of the extracted FIB samples and corresponding TEM images are shown in Figure 18(b), Figure 18(c). The dotted lines represent the area within the $\gamma^{\prime}$ precipitate (Figure 18(d)) where the shearing effect is most pronounced.

For DSLs, similar findings have been reported in [49], in which an FIB sample (10 $\mu \mathrm{m}$ below the fracture surface) (sub-microstructure in the HE brittle zone)

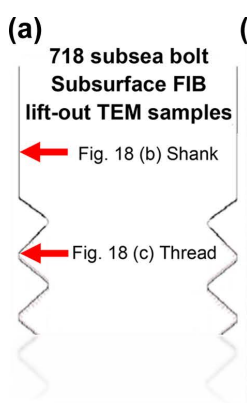

(b)

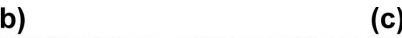

(d)

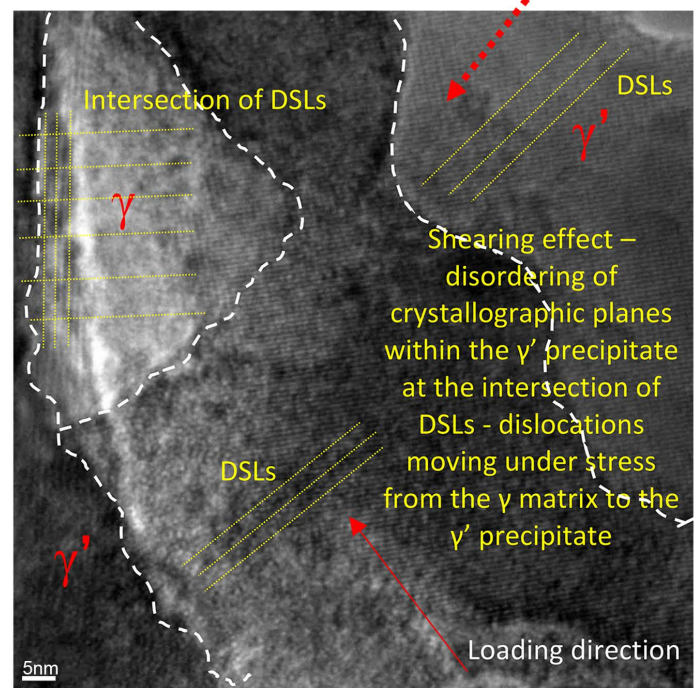

Figure 18. Schematic diagram of the 718 subsea bolt; the location of the extracted FIB TEM samples is shown in (a). (b) and (c) show the distribution of sheared $\gamma^{\prime}$ precipitates at shank and thread regions, respectively. Panel (d) is the higher magnification of (c) and shows the sheared $\gamma^{\prime}$ precipitate along with DSLs in between. 
was extracted. Extreme plastic deformation with DSLs detected, which is similar to what was observed at higher magnification at the bolt thread region, is shown in Figure 18(d). In addition to DSLs, in between the sheared $\gamma^{\prime}$ precipitate, the $\gamma$ matrix is clearly observed owing to the shearing effect caused by the disordering of crystallographic planes within the $\gamma^{\prime}$ precipitate by DSLs (moving under stress from the $\gamma$ matrix to the $\gamma^{\prime}$ precipitate) and hydrogen atoms. These sheared $\gamma^{\prime}$ are the potential source of surface/subsurface cracking as hydrogen accumulates under $\mathrm{CP}$ at these transgranular sites, which creates stress-concentrated regions. This may also be the reason why these subsea 718 bolts in-service (under overtightening and overloading conditions) may have stud or thread fracture. In-service pre-tensioning and loading produces high driving force, and the available slip system operates at high coherency strain regions, where hydrogen atoms accumulate close to the surface of the bolt; this phenomenon promotes the further shearing and elongation of $\gamma^{\prime}$ particles at the threads and shank edge (with a 50-nm size) but not in the bulk (where the maximum size of $\gamma^{\prime}$ is $30 \mathrm{~nm}$ ). Some available DSLs are induced at the manufacturing level during the rolling of shank and threads; this process may produce sheared surface $\gamma^{\prime}$ precipitates prior to deploying the bolts in-service. It is reasonable to infer that for 718 bolts, sheared $\gamma^{\prime}$ sites (see Figure 18) along with the points of intersection of slip lines undergo nanovoid coalescence to exhibit the transgranular mode of surface cracking. Thus, these transgranular nanocracks on bolt surface and subsurface under loading result in the brittle fracture mode at the threads and shank surface, compared to the ductile fracture of the bulk.

During the manufacturing, the rolling of bolts considerably alters their structure by inducing lattice mismatch regions [50]. The concentration of these regions was higher at the surface than at the bulk, which resulted in the extensive precipitation of $\gamma^{\prime \prime}$ disks at the edge of the bolt, where their size surpassed even the 100-nm limit (Figure 17, Figure 18); the cold rolling of threads after the heat treatment resulted in sheared oversized $50-\mathrm{nm} \gamma^{\prime}$ precipitates at the surface/subsurface of the bolt. The structure difference between the two phases might also have an effect on their interaction with hydrogen atoms; however, this needs to be resolved as a future work by observing the PLC effect of 718 specimens with a desired microstructure (S1, S2, S3, S4, S5, and bolt specimens from the bulk and subsurface).

The presence of $\gamma^{\prime \prime}$ (apart from providing remarkable strength, $0.2 \% \sigma_{\mathrm{YS}} 880$ $\mathrm{MPa}$ ) makes the 718 bolt microstructurally unstable; in addition, approximately 50-nm spherical $\gamma^{\prime}$ particles have the potential for surface cracking under cathodic protection. There is consensus among researchers regarding the HE theory specifically for Inconel 718 that transgranular cracks are initiated at the intersection of DSLs [15] [16] [17] where the embryos of nanocracks form. Cassagne et al. [12] have postulated the presence of HEDE intergranular cracking at the grain boundary. However, until now, no attention has been paid to characterizing the individual role of nanoprecipitates at subsurface regions for crack in- 
itiation. Whereas, the hydrogen-assisted surface/subsurface cracking equation for API 718 subsea bolts (cold rolling of threads after the heat treatment) can be written as: $\mathrm{CP}$ under service loading + nanoscale oversized $\gamma^{\prime}$ precipitates + metastable $\gamma^{\prime \prime}$ precipitates + intergranular precipitates (if any) $=$ hydrogen-assisted surface cracking. The morphological data from this study will act as a reference in the future for observing the PLC effect in CRA 718 bolts at subsea temperature and under cathodic hydrogen charging. Therefore, this study includes some non-standard heating parameters to include more 718 variants for extensive PLC comparison.

\section{Conclusion}

718 bolts are used subsea for the integration of flanges and critical well components under CP. It's important to understand microstructure if the manufacturing route of the 718 bolts is changed. The current study evaluated a change in the manufacturing route and how this affected the bolt nanostructure at bulk and surface/subsurface regions (compared to $718 \mathrm{RB}$ under identical API aging and some non-standard heating variants) and subsequently demonstrated the hydrogen-assisted surface cracking theory for the CRA subsea bolts. The following key observations can be made. 1) Under identical API aging, S2 from RB produces an $8 \%$ - 15\% decrease in hardness (10 - 20-nm $\left.\gamma^{\prime}, 340 \mathrm{HV}\right)$ and a $4.5 \%$ decrease in yield strength compared to those of subsea bolts S6 and S7 [approximately 30-nm $\gamma^{\prime}$ and $30-50-\mathrm{nm} \gamma^{\prime \prime}$ in the bulk (370 HV), and approximately 50-nm $\gamma^{\prime}$ and $50-100-\mathrm{nm} \gamma^{\prime \prime}$ at subsurface (400 HV)]. 2) The cold rolling of threads after the API heat treatment of bolts resulted in the shearing of oversized 50-nm $\gamma^{\prime}$ precipitates at surface/subsurface regions. 3) These sheared transgranular sites with DSLs attract hydrogen and may promote brittle cracking at the outer periphery of the bolts. 4) The morphological and tensile data of current 718 variants presented in this study will assist with future studies on the PLC effect at subsea environments.

\section{Acknowledgments and Funding}

All microscopy was carried out using facilities at the University of Leicester. The author is also grateful to experimental officer Vinay Patel and laboratory technician Graham Clark for their contributions. The author wishes to thank "Titanium Engineers" and "C.H. Robinson Europe BV" for providing the materials, and EPSRC UK for financial support.

\section{Data Availability}

The processed data required to reproduce these findings are available to download from [http://hdl.handle.net/2381/40291], and appear in collection at University of Leicester Theses under Leicester research archive.

\section{Conflicts of Interest}

The authors declare no conflicts of interest regarding the publication of this paper. 


\section{References}

[1] DeBarbadillo, J.J. and Mannan, S.K. (2012) Alloy 718 for Oilfield Applications. JOM, 64, 265-270. https://doi.org/10.1007/s11837-012-0238-z

[2] Rorvik, G., Kirkemo, F. and Haaland, B.O. (2014) Fasteners in Subsea Applications: End User Experiences and Requirements. Proceedings of the ASME 2014 33rd International Conference on Ocean, Offshore and Arctic Engineering, San Francisco, California, 8-13 June 2014, Paper No: OMAE2014-24520. https://doi.org/10.1115/OMAE2014-24520

[3] Ferreira, P.J., Robertson, I.M. and Birnbaum, H.K. (1998) Hydrogen Effects on the Interaction between Dislocations. Acta Materialia, 46, 1749-1757. https://doi.org/10.1016/S1359-6454(97)00349-2

[4] Sofronis, P. and Robertson, I.M. (2002) Transmission Electron Microscopy Observations and Micromechanical/Continuum Models for the Effect of Hydrogen on the Mechanical Behaviour of Metals. Philosophical Magazine A, 82, 3405-3413. https://doi.org/10.1080/01418610208240451

[5] Oriani, R.A. (1972) A Mechanistic Theory of Hydrogen Embrittlement of Steels. Berichte der Bunsengesellschaft für physikalische Chemie, 76, 848-857.

[6] Troiano, A.R. (1960) The Role of Hydrogen and Other Interstitials in the Mechanical Behavior of Metals. Transactions of the American Society of Metals, 52, 54-80.

[7] API (2004) Specification of Nickel Base Alloy 718 (UNS N07718) for Oil and Gas Drilling and Production Equipment. American Petroleum Institute, Washington DC.

[8] Rezende, M.C., Araujo, L.S., Gabriel, S.B., Dos Santos, D.S. and De Almeida, L.H. (2015) Hydrogen Embrittlement in Nickel-Based Superalloy 718: Relationship between $\gamma+\gamma$ " Precipitation and the Fracture Mode. International Journal of Hydrogen Energy, 40, 17075-17083. https://doi.org/10.1016/j.ijhydene.2015.07.053

[9] Liu, L., Tanaka, K., Hirose, A. and Kobayashi, K.F. (2002) Effects of Precipitation Phases on the Hydrogen Embrittlement Sensitivity of Inconel 718. Science and Technology of Advanced Materials, 3, 335-344. https://doi.org/10.1016/S1468-6996(02)00039-6

[10] Nice, P., Strong, R., Bailey, W.M., Rorvik, G., Olsen, J.H. and Mobberley, T.G. (2014) Hydrogen Embrittlement Failure of a Precipitation Hardened Nickel Alloy Subsurface Safety Valve Component Installed in a North Sea Seawater Injection Well. NACE International, San Antonio.

[11] Shademan, S.S., Martin, J.W. and Davis, A.P. (2012) UNS N07725 Nickel Alloy Connection Failure. NACE International, Houston.

[12] Cassagne, T., Bonis, M., Hillis D. and Duret, C. (2008) Understanding Field Failure of Alloy 718 Forging Materials in HP/HT Wells. Proc. of EuroCorr, Edinburgh, European Federation of Corrosion, 7-11 September 2008, 1-13.

[13] Oradei-Basile, A. and Radavich, J.F. (1991) A Current T-T-T Diagram for Wrought Alloy 718. In: Loria, E.A., Ed., Superalloys 718,625 and Various Derivatives, The Minerals, Metals, and Materials Society, Warrendale, 325-335. https://doi.org/10.7449/1991/Superalloys 1991 $325 \quad 335$

[14] Saunders, N., Fahrmann, M. and Small, C.J. (2000) The Application of Calphad Calculations to Ni-Based Superalloys. In: Green, K.A., Pollock, T.M. and Kissinger, R.D., Eds., Superalloys 2000, TMS, Warrendale, 803.

[15] Zhang, Z.B., Obasi, G., Morana, R. and Preuss, M. (2016) Hydrogen Assisted Crack Initiation and Propagation in a Nickel-Based Superalloy. Acta Materialia, 113, 
272-283. https://doi.org/10.1016/j.actamat.2016.05.003

[16] Tarzimoghadam, Z., Ponge, D., Klöwer, J. and Raabe, D. (2017) Hydrogen-Assisted Failure in Ni-based Superalloy 718 Studied Under in Situ Hydrogen Charging: The Role of Localized Deformation in Crack Propagation. Acta Materialia, 128, 365-374. https://doi.org/10.1016/j.actamat.2017.02.059

[17] Demetriou, V., Robson, J.D., Preuss, M. and Morana, R. (2017) Study of the Effect of Hydrogen Charging on the tensile Properties and Microstructure of Four Variant Heat Treatments of Nickel Alloy 718. International Journal of Hydrogen Energy, 42, 23856-23870. https://doi.org/10.1016/j.ijhydene.2017.02.149

[18] Mehl, M.E. and Lippold, J.C. (1997) Effect of $\delta$ Phase Precipitation on the Repair Weldability of Alloy 718. In: Loria, E.A., Ed., Superalloys 718,625, 706 and Various Derivatives, The Minerals, Metals, \& Materials Society, Pittsburgh, 731-741.

https://doi.org/10.7449/1997/Superalloys $1997 \quad 731 \quad 741$

[19] Cozar, R. and Pineau, A. (1973) Morphology of y' and y" Precipitates and Thermal Stability of Inconel 718 Type Alloys. Metallurgical Transactions, 4, 47-59. https://doi.org/10.1007/BF02649604

[20] Saleem, B., Dong, H.B. and Patel, V. (2019) Effect of Aging on the Strength of Corrosion-Resistant Incoloy Alloys 945 and 945X: A Microstructural Perspective. Materials Science and Engineering. A, 748, 327-336. https://doi.org/10.1016/j.msea.2019.01.114

[21] Meng, C.G., Guo, J.T. and Hu, Z.Q. (1996) Relationship between Bonding Characteristics and Mechanical Properties of $\mathrm{L}_{2}$ Intermetallics. Journal of Alloys and Compounds, 237, 139-143. https://doi.org/10.1016/0925-8388(95)02027-6

[22] Hagel, W.C. and Beattie, H.J. (1964) Iron and Steel Institute Special Report. Iron and Steel Institute, London, 98.

[23] Niang, A., Viguier, B. and Lacaze, J. (2010) Some Features of an Isothermal Solid-State Transformations in Alloy 718. Materials Characterization, 61, 525-534. https://doi.org/10.1016/j.matchar.2010.02.011

[24] Dehmas, M., Lacaze, J., Niang, A. and Viguier, B. (2011) TEM Study of High Temperature Precipitation of Delta Phase in Inconel 718 Alloy. Advances in Materials Science and Engineering, 2011, Article ID: 940634. https://doi.org/10.1155/2011/940634

[25] Ramaswamy, V., Swann, P.R. and West, D.R.F. (1972) Observations on Intermetallic Compound and Carbide Precipitation in Two Commercial Nickel-Base Superalloys. Journal of the Less Common Metals, 27, 17-26. https://doi.org/10.1016/0022-5088(72)90100-2

[26] Ghosh, S., Yadav, S. and Das, G. (2008) Study of Standard Heat Treatment on Mechanical Properties of Inconel 718 Using Ball Indentation Technique. Materials Letters, 62, 2619-2622. https://doi.org/10.1016/j.matlet.2008.01.001

[27] Sims, C.T., Stoloff, N.S. and Hagel, W.C. (1987) Superalloys II. John Wiley \& Sons, New York.

[28] Fournier, L., Delafosse, D. and Magnin, T. (1999) Cathodic Hydrogen Embrittlement in Alloy 718. Materials Science and Engineering: A, 269, 111-119. https://doi.org/10.1016/S0921-5093(99)00167-7

[29] Liu, L., Zhai, C., Lu, C., Ding, W., Hirose, A. and Kobayashi, K.F. (2005) Study of the Effect of $\delta$ Phase on Hydrogen Embrittlement of Inconel 718 by Notch Tensile Tests. Corrosion Science, 47, 355-367.

[30] Azadian, S., Wei, L.Y. and Warren, R. (2004) Delta Phase Precipitation in Inconel 718. Materials Characterization, 53, 7-16. 
https://doi.org/10.1016/j.matchar.2004.07.004

[31] Paulonis, D.F., Oblak, J.M. and Duvall, D.S. (1969) Precipitation in Nicket-Based Alloy 718. ASM (Amer. Soc. Metals), Trans. Quart, 62, 611-622.

[32] Sundararaman, M., Mukhopadhyay, P. and Banerjee, S. (1988) Deformation Behaviour of $\gamma$ ' Strengthened Inconel 718. Acta Metallurgica, 36, 847-864. https://doi.org/10.1016/0001-6160(88)90139-3

[33] Oblak, J.M., Paulonis, D.F. and Duvall, D.S. (1974) Coherency Strengthening in Ni Base Alloys Hardened by DO $22 \gamma$ ' Precipitates. Metallurgical Transactions, 5, Article No. 143.

[34] Radavich, J.F. (1989) The Physical Metallurgy of Cast and Wrought Alloy 718. In: Loria, E.A., Ed., Superalloy 718 Metallurgy and Applications, The Minerals, Metals \& Materials Society, Warrendale, 229-240.

[35] Jothi, S., Merzlikin, S.V., Croft, T.N., Andersson, J. and Brown, S.G.R. (2016) An Investigation of Micro-Mechanisms in Hydrogen Induced Cracking in Nickel-Based Superalloy 718. Journal of Alloys and Compounds, 664, 664-681. https://doi.org/10.1016/j.jallcom.2016.01.033

[36] LaCoursiere, M.P. Aidun, D.K. and Morrison, D.J. (2017) Slow Strain Rate Testing for Hydrogen Embrittlement Susceptibility of Alloy 718 in Substitute Ocean Water. Journal of Materials Engineering and Performance, 26, 2337-2345. https://doi.org/10.1007/s11665-017-2675-x

[37] Obasi, G., Zhang, Z., Sampath, D., Morana, R., Akid, R. and Preuss, M. (2018) Effect of Microstructure and Alloy Chemistry on Hydrogen Embrittlement of Precipitation-Hardened Ni-Base Alloys. Metallurgical and Materials Transactions A, 49, 167-1181. https://doi.org/10.1007/s11661-018-4483-9

[38] ASTM E112-96 (2004) Standard Test Methods for Determining Average Grain Size, ASTM International, West Conshohocken, PA.

[39] Whitmore, L., Leitner, H., Povoden-Karadeniz, E., Radis, R. and Stockinger, M. (2012) Transmission Electron Microscopy of Single and Double Aged 718Plus Superalloy. Materials Science and Engineering. A, 534, 413-423. https://doi.org/10.1016/j.msea.2011.11.089

[40] Ding, R. (2010) Grain Boundary Segregation in Ni-Base (718 Plus) Superalloy. Materials Science and Technology, 26, 36-40. https://doi.org/10.1179/174328408X385836

[41] Turnbull, A., Ballinger, R.G., Hwang, I.S., Morra, M.M., Psaila-Dombrowsik, M. and Gates, R.M. (1992) Hydrogen Transport in Nickel-Base Alloys. Metallurgical Transactions A, 23, 3231-3244. https://doi.org/10.1007/BF02663432

[42] Pressouyre, G.M. and Bernstein, I.M. (1979) A Kinetic Trapping Model for Hydrogen-Induced Cracking. Acta Metallurgica, 27, 89-100. https://doi.org/10.1016/0001-6160(79)90059-2

[43] Dai, S. and Liu, W. (2010) First-Principles Study on the Structural, Mechanical and Electronic Properties of $\delta$ and $\gamma$ " Phases in Inconel 718. Computational Materials Science, 49, 414-418. https://doi.org/10.1016/j.commatsci.2010.05.031

[44] Lu, X., Wang, D., Wan, D., Zhang, Z.B., Kheradmand, N. and Barnoush, A. (2019) Effect of Electrochemical Charging on the Hydrogen Embrittlement Susceptibility of Alloy 718. Acta Materialia, 179, 36-48. https://doi.org/10.1016/j.actamat.2019.08.020

[45] Randle, V. (2004) Twinning-Related Grain Boundary Engineering. Acta Materialia, 52, 4067-4081. https://doi.org/10.1016/j.actamat.2004.05.031 
[46] Palumbo, G. and Aust, K.T. (1995) Solute Effects in Grain-Boundary Engineering. Canadian Metallurgical Quarterly, 34, 165-173. https://doi.org/10.1179/cmq.1995.34.3.165

[47] Seita, M., Hanson, J.P., Gradečak, S. and Demkowicz, M.J. (2015) The Dual Role of Coherent Twin Boundaries in Hydrogen Embrittlement. Nature Communications, 6, Article No. 6164. https://doi.org/10.1038/ncomms7164

[48] Kagay, B., Findley, K., Coryell, S. and Nissan, A.B. (2016) Effects of Alloy 718 Microstructure on Hydrogen Embrittlement Susceptibility for Oil and Gas Environments. Materials Science and Technology, 32, 697-707. https://doi.org/10.1080/02670836.2016.1139225

[49] Li, X., Zhang, J., Akiyama, E., Fu, Q. and Li, Q. (2019) Hydrogen Embrittlement Behavior of Inconel 718 Alloy at Room Temperature. Journal of Materials Science \& Technology, 35, 499-502. https://doi.org/10.1016/j.jmst.2018.10.002

[50] Kou, S. (2003) Welding Metallurgy. 2nd Edition, John Wiley and Sons, New York. 